ASSESSING PROGRAM DELIVERY FROM THE PERSPECTIVE OF SERVICE $\frac{18}{1132}$ PROVIDERS: THE ONTARIO EARLY YEARS CENTRES' SCHOOL READINESS $\stackrel{523}{2008}$

PROGRAM

\author{
by \\ Ziba Saadati \\ B.Sc. (Honours), York University, 2006
}

\begin{abstract}
A Major Research Paper
Presented by Ryerson University

In partial fulfillment of the requirements for the degree of

Master of Arts

in the program of

Early Childhood Studies
\end{abstract}

Toronto, Ontario, Canada, 2008

CC Ziba Saadati 2008 
UMI Number: EC53442

\section{INFORMATION TO USERS}

The quality of this reproduction is dependent upon the quality of the copy submitted. Broken or indistinct print, colored or poor quality illustrations and photographs, print bleed-through, substandard margins, and improper alignment can adversely affect reproduction.

In the unlikely event that the author did not send a complete manuscript and there are missing pages, these will be noted. Also, if unauthorized copyright material had to be removed, a note will indicate the deletion.

\section{UMI}

UMI Microform EC53442

Copyright 2009 by ProQuest LLC

All rights reserved. This microform edition is protected against unauthorized copying under Title 17, United States Code.

ProQuest LLC

789 East Eisenhower Parkway

P.O. Box 1346

Ann Arbor, MI 48106-1346 


\section{Author's Declaration}

I hereby declare that I am the sole author of this major research paper.

I authorize Ryerson University to lend this paper to other institutions or individuals for the purpose of scholarly research.

I further authorize Ryerson University to reproduce this paper by photocopying or by other means, in total or in part, at the request of other institutions or individuals for the purpose of scholarly research.

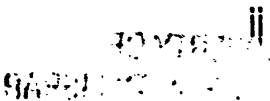




\title{
ASSESSING PROGRAM DELIVERY FROM THE PERSPECTIVE OF SERVICE PROVIDERS: THE ONTARIO EARLY YEARS CENTRES' SCHOOL READINESS
}

\section{PROGRAM}

C) Ziba Saadati 2008

\author{
Master of Arts \\ Early Childhood Studies \\ Ryerson University
}

\begin{abstract}
This paper assesses the School Readiness program as delivered in two Ontario Early Years Centres (OEYCs) in Toronto. Information about program goals and delivery methods gleaned from interviewing three Child Development Consultants who ran the program in the last year is analyzed within the context of existing scholarship on and practices in early childhood learning and development. The interviewers' observations and comments form the basis for the assessment of the effectiveness of the OEYC School Readiness program. An important part of assessing effectiveness is determining whether the OEYCs and program workers have set clearly defined learning outcomes for program participants and how, if at all, the program measures these outcomes.
\end{abstract}

In assessing program effectiveness, one of the factors considered is to what extent the OEYCs acknowledge and address the needs of an important demographic: immigrant children (and their support network of parents/caregivers and families). The observations and recommendations made in this study are intended to help service providers in the OEYCs develop a best practice model for program delivery, including arriving at a better sense of how they conceive of school readiness.

Key Words: Ontario Early Years Centres, school readiness, children, immigrant families 


\section{Acknowledgements}

First, I would like to thank Dr. Hyacinth Simpson for all her guidance and support in helping me to complete my MRP. I am very thankful for all you have done for me on this journey. I also very much appreciate the feedback that Dr. Mehru Ali and Dr. Rachel Berman have given me as my second reader and chair of my oral examining committee respectively.

I would also like to thank the supervisor at the Ontario Early Years who allowed me to use his site for my study, as well as the participants who gave up their time to complete the interview.

This paper would never have been completed if it had not been for all the assistance and moral support my family -my husband, parents, sister, and mother-in-law-have provided me. Lastly, I dedicate this paper to my son Kian, who has given so much more meaning to my life. 


\section{Table of Contents}

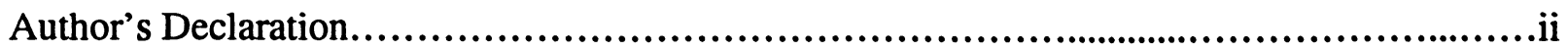

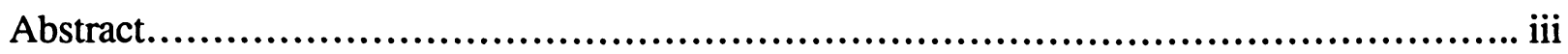

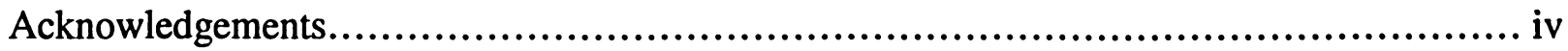

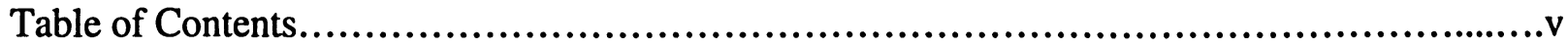

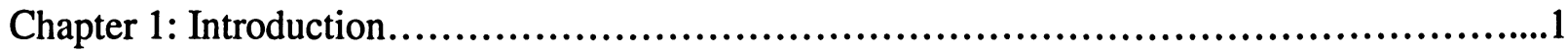

1.1 The Ontario Early Years Centres: History, Structure and Scope.............................5

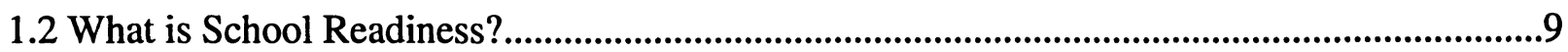

1.3 Research on School Readiness and Early Years Learning- Literacy, Numeracy, and Socio-

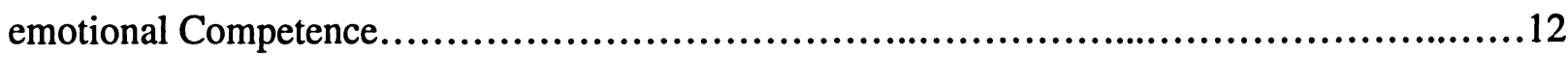

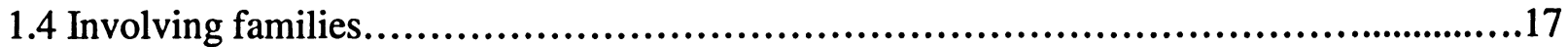

1.5 What are we doing, why, who will it be for?

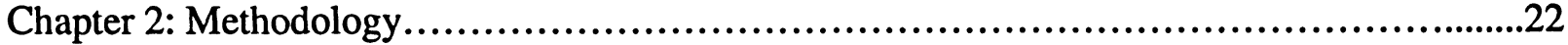

2.1 Researcher's Characteristics: Personal Reflections.....................................22

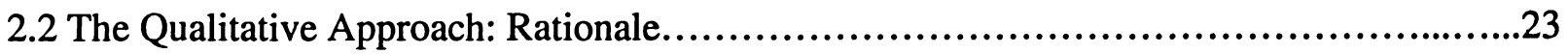

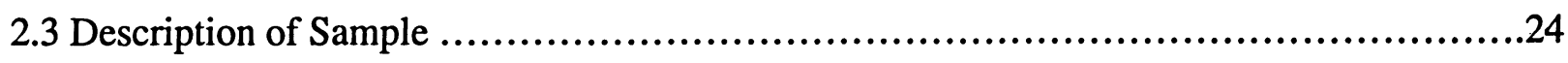

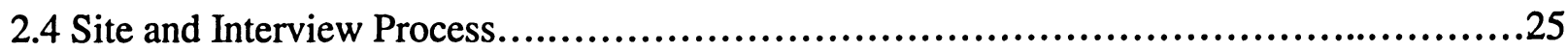

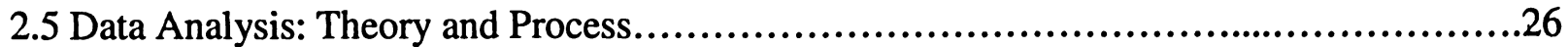

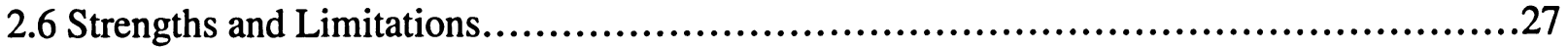

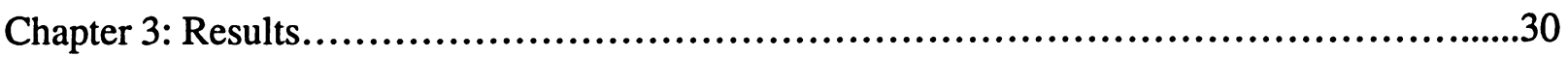

3.1 How is the School Readiness program run by the Ontario Early Years?..................................30

3.2 To what extent do the Ontario Early Years prepare children for school readiness?................39 
3.3 Was there, from the perspective of the CDCs, any indication of a difference between those who participated versus those who did not?

3.4 What are the positives outcomes and challenges faced while conducting the program?.

3.5 Implications for immigrant families?

Chapter 4: Discussion.

4.1 How is the School Readiness program run by the Ontario Early Years?

4.2 To what extent do the Ontario Early Years prepare children for school readiness? .65

4.3 Was there any indication of a difference between those who participated versus those who did not?.

4.4 What are the positives outcomes and challenges faced while conducting the program?. .68

4.5 Implications for immigrant families? .69

4.6 Recommendations. .71

4.7 Limitations of the Study. .73

References . .75

Appendices 82 


\section{Chapter 1: Introduction}

Research has shown that the early years are a critical period in a child's life where the right kind of preparation can provide the necessary skills for success within the school system from pre-school to later educational training (Landry, Swank, Smith, Assel, \& Gunnewig, 2006). This realization has resulted in a variety of programs across North America such as Head Start (Administration for Children and Families (ACF), 2006), which is a targeted program in the US that saw its first incarnation in 1965, the provincially-based Best Start (Ministry of Children and Youth Services (MCYS), 2007b), which came into being in 1992 in Ontario, Canada, as well as the Ontario Early Years Centres (MCYS, 2005) instituted in 2002 and which are at the centre of this study. In order for early years programs to receive funding, government agencies require that they demonstrate how they positively impact child development (Government Accounting Office (2003) in Snow, 2006). This MRP takes its cue from government agencies' insistence on evidence of program effectiveness, but whereas these agencies' goal is ensuring financial viability and accountability, the objectives of this study is a thorough assessment of the School Readiness program in two Ontario Early Years Centres (OEYC), with emphasis on how the program is delivered, including how the Child Development Consultants (CDCs) running the program assess its effectiveness and whether the program itself has built-in mechanisms for selfassessment. After four years during which no kind of formal assessment has been made, the OEYCs are ripe for evaluation.

The focus on program delivery and program workers' practice in this study is not meant to suggest that this is the only point of entry into assessing the effectiveness of the Ontario Early Years School Readiness program. Indeed, it would be just as viable to assess effectiveness from the perspective of those being served by the program, such as the parents and families of the 
children involved, to determine whether the program assists parents and families in supporting and furthering clearly identified positive learning and development outcomes in their children and fosters better parent-child interactions. As well, program effectiveness could also be assessed by attempting a qualitative analysis of the developmental and learning outcomes demonstrated in the children participating in the program, particularly as those outcomes are measured and/or observed by kindergarten and Grade One teachers and other trained practitioners in the schools. Assessment could also focus on understanding how parent-child participation facilitates/hinders children's development and recognizing what the benefits to participating in such programming are as a means of determining whether the program should be supported by parents, communities, and government funding, and what changes-if any-are needed to improve program effectiveness and delivery. The decision to focus on program delivery and program workers' praxis in this study is in part informed by the limits of the current study: because of its scope a Major Research Paper can only offer a partial assessment of program effectiveness and as such the researcher has to concentrate on only one point of assessment. But even more so, the research emphasis taken in this study is motivated by the absence of clear guidelines within the Ontario Early Years Centres as to how to run the School Readiness program. In fact, a thorough review of current practices indicates that the Child Development Consultants who run the School Readiness program are not provided with any formal training or professional development to enable them to deliver the program more effectively. Each $\mathrm{CDC}$ delivers the program according to her own understanding of what the children and parents participating in the program need, often resulting in a wide variation in practice. Furthermore, the Ontario Early Years Centres have adopted no clear definition of school readiness and, therefore, the CDCs do not work from a common template of desired learning and development outcomes that each program run should 
achieve. In addition, in the initial stages of preparing this study, the researcher learned from an OEYC site supervisor that the School Readiness program had not yet been evaluated and that program deliverers would welcome and benefit from outside evaluation of the program. It is clear, then, that an important part-possibly even a necessary first step-in evaluating the effectiveness of the Ontario Early Years Centres School Readiness program is assessing program delivery and providing recommendations for a best practice model. The researcher foresees a future study in which a fuller assessment of program effectiveness will incorporate the perspectives of parents and families and other child development practitioners.

The current study looks at the OEYC School Readiness program offered in two Toronto ridings. The data presented incorporates information gathered in one-on-one interviews with three Child Development Consultants (CDCs) who run the program in the two Toronto ridings in order to provide a starting point for analysis and to understand the program's strengths and weaknesses. The following questions drive the study: a) What is the current practice in delivering the School Readiness program in the Ontario Early Years Centres?; b) How is school readiness defined in the OEYCs according to individuals offering the program?; c) What are the benefits and challenges to running these programs?; and d) What changes should be made to the program so that in the future it better meets the needs of families and children?

An important aspect of assessing program delivery is determining to what extent those offering the School Readiness program acknowledge and address the cultural perspectives and needs of immigrant families and their pre-school age children. For the purposes of this paper, newcomer families are defined as those who have lived permanently for a relatively short time (approximately 5 years or less) in Canada. Although newcomer families are not always unfamiliar with Canadian/ Dominant Anglo-white culture and are not always non-English/non- 
French speakers, the emphasis here when the term "newcomer" is used is on families with English (as the OEYCs are Ontario-based) as a second language from regions with marked cultural differences and expectations around early childhood development and learning from those of the dominant Canadian culture. Note that in this paper there is no assumption that "immigrant" is synonymous with "newcomer." In fact, this study is critical of the practice of using these terms interchangeably because such a practice suggests that a) people who were not born in Canada cannot claim Canadian identity; and b) "immigrant" means non-white Canadian.

There are a number of reasons for addressing the School Readiness program's response to members of immigrant communities. For one, Ontario attracts the largest number of immigrants to Canada (Statistics Canada, 2007). Approximately half of Toronto's population currently comprises immigrants. In 2007 , official documents reported the percentage of newcomers in the city of Toronto (meaning those recently arrived in the previous five years) at 59.8\% (Statistics Canada, 2007). For another, the Toronto District School Board (TDSB) noted that in 2004-05, 25\% of elementary students were born outside of Canada and approximately half spoke a mother-tongue that was not English (2006). As well, the TDSB noted that in senior kindergarten, there was a performance gap, not only between the sexes (i.e. girls tend to score higher than boys), but also between ESL and non-ESL students (with the former performing more poorly). ESL students were twice as likely to be in the bottom $10 \%$ of scores on the Early Development Instrument's "physical health and development" and "language and cognitive development" domains. The gap between the two groups was found to be largest when looking at the domain "communication skills and general knowledge" (TDSB, 2006). Also significant is the fact that the OEYCs have also identified the importance of this demography in its Starting right: A better tomorrow for children document by stating explicitly that the Centres' 
programming is to be made "accessible to a broad range of the diverse populations that make up Toronto" (OEYC, 2004, p.2). Furthermore, as researchers, including Ali and Kilbride (2004) and Albanese (2005), have pointed out, immigrant parents sometimes find themselves at odds with (early childhood) educators in Canada because of cultural differences in educational philosophies as different cultures often have their own ideas about how children should be socialized and what outcomes take priority in childhood learning and development. Clearly, meeting the school readiness needs of the children of newcomer families is important to integrating immigrant communities into Canadian life and thus it is necessary to assess the program's record of delivery in this regard.

\subsection{The Ontario Early Years Centres: History, Structure, and Scope}

The Ontario Early Years Centres are funded by the Ministry of Community, Family, and Children's Services and run under larger umbrella agencies such as Family Day Care Services, Macaulay Child Development Centre, and the Mothercraft Institute for Early Development. The OEYCs exists alongside and are supported by other family and early childhood development programs and services in the province such as Healthy Babies Healthy Children, the Infant Hearing Program, services for special needs (i.e. hearing, seeing, speech and language therapies), as well as opportunities for early learning and child care (MCYS, 2007)—all of which fall under the larger provincial initiative known as Best Start mentioned earlier. In fact, the OEYCs themselves offer a range of programming. Alongside the School Readiness program that is intended to prepare children who will be entering Kindergarten (for the younger ones in the 0-6 age range) or Grade One (for those closer to 6 years) in September of the year following their participation in the program, the OEYCs also offer a mix of supports-such as literacy and 
nutrition programs, resources for parents/caregivers, and parent/caregiver-child interactive programs-tailored to meet the unique needs of each community (MCYS, 2003).

The OEYCs are the direct result of the government commissioned Mustard and McCain Early Years Report released in 1999. The report was based on the Toronto District School Board's then existing 52 Parenting and Family Literacy centres, which were first established in 1981. These centres, now numbering 54, continue to exist alongside the OEYCs although, unlike the OEYCs that are based in/attached to individual ridings across the province, the Parenting and Family Literacy centres are attached to inner-city elementary schools across Toronto. The Parenting and Family Literacy centres are free for children 0-6 years of age and their parents/caregivers, as are the programs offered through the OEYCs; and the centres run playbased programs that promote literacy and numeracy skills in a culturally inclusive environment that prepare children for school entry (TDSB, 2007). As such, there is some overlap in school readiness preparation between the Parenting and Family Literacy centres and the OEYCs.

Currently, there are 103 OEYCs across Ontario, with at least one in every riding. 22 of those 103 OEYCs are located in Toronto. The first of the OEYCs opened across the province in 2002 and were housed in what were actually pre-existing Child and Parenting Centres (Community Social Planning of Toronto (CSPT), n.d.). In fact, the first OEYCs used the resources—and employees—of the pre-existing centres but changed the centres' mandate to realign them more closely with the philosophy of the newly-instituted OEYCs. That philosophy, simply put, is to prepare children for school and run parent-child interactive programs that foster the healthy development of children. An important directive behind opening the OEYCs was "to fill gaps, prevent duplication, and effectively use available early years skills and resources" 
(CSPT, n.d.) In addition, the OEYCs were expected to provide quality research-based programs and activities to support/inform program delivery, particularly the School Readiness program.

The Mustard and McCain Early Years Report that resulted in the OEYCs was in response to a new understanding of the relationship between brain development in a child's early years and later learning (MCYS, 2007c). The aim of the study was to provide recommendations for the best ways to prepare children for later success. The researchers recognized that the development of the brain in the early years of a child's life (0-6 years) sets the basis for his/her competence and coping skills. The findings indicated that a child's experience and interactions with adults and other children are important and that initiatives for early childhood development and learning need to recognize the role that experience and interactions play in children's brain development. In order to facilitate optimum brain development in children, and recognizing the important role of parents/caregivers, one recommendation was that parents need to play a key role in early child development and parenting programs. Interestingly enough, it was also found that poor outcomes were observed in children from all socio-economic backgrounds and that sub-standard performance could be traced back to poor early brain development, which made a compelling case for establishing a more universal, province-wide program offered through , unlike the scope of Head Start in the US or even the more closely-targeted Parenting and Family Literacy centres that, based on their location, cater more exclusively to inner-city communities in Toronto. As well, the researchers emphasized the role the provincial government needs to play in ensuring that early years initiatives are sensitive to the specific needs of the communities in which they are located.

The Mustard and McCain Early Years Report also identified a number of principles (see Appendix B) at the core of early development and parenting programs, noting among them " $[t]$ he 
effectiveness of early child development centres that are monitored using a developmental readiness-to-learn measure when children enter the school system" (MCYS, 2007c, 139), which is the final of 12 principles listed in the document. The question then arises: If one of the ways of determining the effectiveness of early child development centres is a readiness-to-learn measure for when children enter the school system, then what means/measures have the Ontario Early Years Centres employed in order to assess the success of the School Readiness program each time it runs? Further to this, one has to ask: Do the OEYCs operate the School Readiness program with a clearly stated definition of school readiness and does the program offer any specific guidelines as to how to foster and measure stated learning and development outcomes in children participating in the program?

These and other questions posed earlier in the study will be answered later on when details of program delivery are revealed by the three CDCs interviewed. But it is instructive here to note that there are other school readiness programs in Ontario besides the one offered by the Ontario Early Years Centres and, through initiating a brief comparison with one such program, point to some of the concerns about the OEYCs program that will be developed in subsequent sections of this study. In 2006, for example, the Ontario Trillium Foundation provided a grant to SIRCH Community Services and Consulting to help promote the School's Cool school readiness program that was created in 1998 and which runs across Canada (SIRCH Community Services and Consulting, n.d.). Program delivery is based in two models: a pre-kindergarten program for children aged 3-5 years who have not yet entered kindergarten and a kindergarten model for children already in school. In each model, the program is delivered in twenty four three-hour sessions over three to four mornings a week during a period of six to eight weeks. The program is delivered by certified School's Cool instructors and may be run in conjunction with other 
organizations. While it appears that School's Cool has a clearly outlined program for school readiness, at least as regard setting a program schedule and determining the length of time needed for each program run and ensuring the certification of program workers, there is very little evidence that the same holds true for the OEYCs. But before the structure, or lack thereof, of the OEYCs' program is explored at further length, it is necessary to recap what the current scholarship has to say about "school readiness" and recall the various definitions in use in the context of making preliminary comments about program practice at the OEYCs in order to set the stage for the program assessment.

\subsection{What is School Readiness?}

School readiness appears to comprise three core ingredients: literacy, numeracy, and socio-emotional development. However, it should be noted that there is no agreed upon definition of school readiness (Snow, 2006; Graue, 2006). For example, one school of thought takes a maturationist perspective wherein children are considered ready to enter school when they have "grown old enough and achieved a certain level of maturity" (Snow, 2006, p.10). This is consistent with the age-requirements set by schools (i.e. children should turn 4 by the end of December of the year they will begin school).

Another school of thought holds that there are certain skills children should have in order to be ready for school. School readiness checklists, such as the School Readiness Checklist created by Peggy Gisler and Marge Eberts (Graue, 2006), are created to provide parents with a method for evaluating their children. The problem with checklists such as these is that they are very classroom specific; that is, they often focus more on literacy and numeracy skills. Denham (2006) suggests that a socio-emotional assessment tool should be considered in addition to the literacy and numeracy checklists that are available in assessing school readiness in response to 
research that shows that the socio-emotional aspect of development may be more important in terms of school readiness than literacy and numeracy.

While these three definitions focus on children's school readiness, another school of thought asks whether the focus should be on preparing children for school or the schools for the children, or if it works both ways (Di Santo, 2006). Maxwell \& Bryant (2001) created a document that looked at how to assess school readiness in children. In an effort to create an assessment battery that would help to measure children's school readiness, the researchers defined school readiness as a puzzle with two pieces. The first piece considers the condition of children at the time they enter school in five key areas: health and physical development, social and emotional development, approaches toward learning, language development and communication, and cognition and general knowledge. The second piece looks at the capacity of schools to serve all kindergartners effectively. The researchers noted that while most definitions of school readiness focus on children's skills alone, some states included schools in their assessment and official definition of school readiness.

When determining what skills a child should have to be ready for school, the literature suggests that there is no consensus among professionals (Lewit \& Baker (1995); West, Hausken, \& Collins (1995), in Di Santo, 2006), which may contribute to the difficulty in formalizing a single definition. As well, aside from the problem of measuring socio-emotional competence (Denham, 2006), another problem with attempting to define school readiness is the cultural variations that exist in attempts to arrive at a definition (Graue, 2006). One concern over school readiness testing, especially in multicultural environments such as Toronto and other parts of Ontario, is the fear of marginalizing immigrant families who may not have enough of a grasp of the language of their adopted country to perform well on such tests. Glutting, Barker, and 
Gelardo (1983) found that the socio-economic status and age at time of school entrance among immigrant children when compared to the same factors in their Anglo counterparts, did not account for lower academic readiness in immigrant children. The authors speculated that various cultures may place a high value on different types of learning at different stages such that literacy and numeracy would not be strong indicators of development; rather other characteristics valued by an ethnic group such as social skills, for example, may be more indicative of school readiness within these groups. A definition of school readiness would need to take these variations into consideration as, without allowing for different meanings, a number of children could be sidelined by a system that gives credence only to dominant North American white, Anglo-Saxon values.

In order to facilitate school readiness, the Toronto District School Board (TDSB) outlines what will be expected of children when they begin school and provide suggestions about what parents can do to help prepare their children to enter the school system (TDSB, n.d.). For example, the TDSB states that children will have to share material and space and suggests ways in which parents can help give their children opportunities to interact with other pre-schoolers to practice sharing and taking turns. Other examples are provided and are found in Appendix C. According to the TDSB, a child ready for school will have some literacy and numeracy skills (i.e. a basic recognition of shapes, colours, letters, or words) as well as social skills (i.e. turn taking, asking for help, and sharing).

While it appears that the term "school readiness" places the onus on either individual parents or the schools to prepare children, Di Santo (2006) discussed the possibility of using another term such as "transition to school" that would include all parties involved-children, families, and schools—and emphasize an ongoing collaborative process that would occur before 
a child begins school. Recognizing that the transition to school is a process shows that children and families are influenced by their environments and vice versa and that "school readiness" is not something that occurs over a short period of time.

Because no formal definition of school readiness is provided by the OEYCs, for the purposes of this MRP, a general definition of school readiness may be taken from Snow (2006) who states that "school readiness refers to the state of child competencies at the time of school entry that are important for later success" (p.9), which include literacy and numeracy skills but also, and to a larger extent, socio-emotional skills. This definition is adopted because it best reflects the CDCs' description of their practice and their underlying theory of child development and school readiness. Literacy and numeracy, in the context of this paper, refer to the recognition of some letters, numbers, and sounds as well as the ability of children to communicate not just with their counterparts but with adults as in a coherent manner. Early years programming and more specifically School Readiness Programs, then, may be the connecting factor in preparing minority/immigrant children for the type of school readiness valued by North American culture (Glutting, Barker, \& Gelardo, 1983).

\subsection{Research on School Readiness and Early Years Learning-Literacy, Numeracy, and Socio- emotional Competence}

Because literacy and numeracy are among the most used measures for determining school readiness in North American culture, early years programs have the responsibility to provide preschool children with a basic foundation in these competencies in order to facilitate and enhance their later learning. Two US researchers, Fiorentino and Howe (2004), conducted a study in which children were asked to narrate stories that were later examined for language 
competence and narrative ability as the acquisition of these skills is used to determine the degree of children's school readiness. The researchers noted that children who demonstrated a higher level of language competence told stories that were more organized and chronologically ordered compared to their counterparts, and that there were noticeable differences between preschoolers from low-income and those from high- income families, with the latter demonstrating higher levels of competence. A Canadian study conducted by Maggi, Kohen, Hertzman, and D'Angiulli (2004) also found a correlation between higher competence in preschoolers and their families' higher socio-economic status (SES). Children from lower SES neighborhoods were more likely to be at risk. This finding has implications for School Readiness programs that are located in lower-income communities, and particularly for newcomer families where adultsdespite having a higher level of education (in the 1990s $40 \%$ of immigrants ages $25-54$ but only 23\% of the Canadian-born population in the same age range held university degrees) (Momirov and Kilbride, 2005)—-tend to experience higher rates of unemployment, underemployment and poverty (Shields, 2004). As well, highly competent children may also be affected by SES in that they may not be as stimulated due to a community's-and hence the program/s run out of that community - lack of resources. The authors noted various reasons why this may be the case, including the fact that lower SES neighborhoods have a greater variety of cultures and the community may not be responding adequately to the needs of each cultural group. This and other considerations need to be factored into available programs so that they meet the needs of children and their families; for example, lower income families may need access to more resources in order to provide equitable outcomes for and adequately foster the developmental experiences of their children. 
With this in mind, early years programs that focus on literacy-centered activities may draw on a basic framework that provides children with tools so that they can better express themselves. One example is an experimental intervention program initiated statewide to enhance children's language and early literacy skills in twenty Head Start sites (Landry, Swank, Smith, Assel, \& Gunnewig, 2006). Teachers who received professional development training with respect to early literacy curriculum were able to assist children in making greater gains in their language and literacy skills. These interventions were found to be most effective when full-day classes were held as opposed to half-day classes. Hence, school readiness programs are more than just drop-in programs for the parent and child. Consistency is necessary to experience any gains. Initially, the study found that Head Start programs often did not incorporate a curriculum for enhancing literacy skills due to concerns over overshadowing social-emotional development; however, a program that is able to incorporate literacy, numeracy and socio-emotional development may be what children and families need in order to be well prepared for school. In light of this information, one important consideration for this paper is to look at how those conducting the School Readiness program at the Ontario Early Years Centres prepare their curriculum and which competencies they give priority to.

In a UK study done by Schneider, Ramsay, and Lowerson (2006), the researchers did not find a difference with respect to school readiness attainment (defined as literacy and numeracy) between children who participated in and those who did not participate in the Sure Start program there. School readiness programs, then, may not necessarily improve a child's literacy and numeracy skills or give a child a head start on school readiness. However, the authors did find that there was a direct correlation between those families who used Sure Start and their children's higher personal and social development scores. It is possible that school readiness 
programs, although they may focus some activities on literacy and numeracy, actually develop the social skills necessary for children to succeed later in kindergarten-even when there is no direct focus on developing social competencies. The lack of a difference between the two groups in the Sure Start program may be a consequence of non-participant families already interacting effectively with their children or participating in other groups that foster the same skill development and awareness as a school readiness program. Within the context of this discussion of the Ontario Early Years Centres' program delivery, what might really be occurring is that the kind of interaction between children and their parents/caregivers and between children and their peers deemed important to early brain development may be happening even when such programs are not accessed, which may explain why no difference was observed with respect to literacy and numeracy. However, as was found in the Early Years Study (MCYS, 2007c), early experience improved competence and coping skills—something that all children and parents can only benefit from. Hence, one could argue that whatever the current shortcomings, The Ontario Early Years School Readiness program may offer some benefits in that it provides an opportunity for children to (further) develop their social skills.

Although socio-emotional competence is beginning to be recognized as an important component in children's development and skills competency, hesitancy around incorporating it into a definition of school readiness lies in the concern over how it can be taught and measured (Denham, 2006). Moreover, the suggestion that assessors must look at each individual child rather than assuming there should be a fixed standard for measuring competencies cannot be ignored. Given such concerns, a qualitative means of assessment may be more useful than a quantitative one. Checklists used in determining where a child is at should be used with some discretion. One example of such a checklist is the Nippissing Developmental Screen which is a 
short checklist that has been created to help parents identify the developmental levels of their children age 0-6 years (NDDS, n.d.). While it is emphasized that it is a screen in order to conduct a quick survey of the areas where a child may require some help, there is real danger that some people may use it as a diagnostic tool. Instead, looking at a child's overall qualities may be more appropriate in determining whether a child is ready for school. Denham (2006) found that teachers assessed readiness to learn if a child exhibits positive emotional expressiveness and demonstrates an ability to regulate emotions and behaviours. Readiness to learn, unlike school readiness, focuses less on whether a child has any literacy and numeracy skills and more on the socio-emotional readiness of that child. Children who exhibit such traits were found to be more well-liked and better able to maintain more positive relationships with their teachers and peers.

A similar study was done by looking at the effects of creative dance on the social competence of preschool children in Head Start programs (Lobo\& Winsler, 2006). The researchers found that especially for children deemed to be at risk, such programs were effective at enhancing social competence and facilitated significant gains with respect to appropriate behaviour. At the OEYCs, there are various programs that are offered to help increase children's social competence. One program is called "Play and Learn" where parents/caregivers and their children go to the Ontario Early Years Centre and play together with other children. At the end, the group comes together during which time songs may be sung, and at some sites snacks are offered. Hence, school readiness program "play" activities may be a means through which children may be taught useful tools that can help them succeed later on in the classroom environment (i.e. such as learning to raise their hands at appropriate times, asking for assistance when needed, and learning/playing together in teams). 
A third study, not part of the Ontario Early Years Centre, reviewed a successful program that has helped children learn better coping skills. Called Zippy's Friends, it is a 24 week school-based program that helps children transition from kindergarten to first grade (Monkeviciene, Mishara, \& Dufour, 2006). Children who participated in the program were found to rate higher on behavioral and emotional adaptation in school and were more likely to have more positive reactions to new situations. There is no argument that preparation with respect to literacy and numeracy is important; however, the above examples show that socioemotional competence cannot be ignored due to a lack of a reliable measurement tool for such constructs. Perhaps developing the necessary skills in children does not require measurement to determine how socially developed a child is. Providing the opportunity for children to learn what is and is not socially acceptable, with the realization that this will help enhance their learning later on, is what is needed.

\subsection{Involving families}

One component of the various programs run by the OEYCs is that they encourage parentchild interactions. Research shows that parents are concerned about their children beginning school and as a result try to judge whether their children are ready for kindergarten (Di Santo, 2006). Often times, parents place greater emphasis on cognitive skills (literacy and numeracy) rather than on socio-emotional skills and the importance of learning through play. Despite the realization that preschool programs are of great importance to children, the effectiveness of such programming falls to a large extent on the support that parents provide at home and their involvement in such programs (Driessen, Smit, \& Sleegers, 2005). In order to garner that support, parents need to be made aware of the benefits these programs have for their children. In addition, programs being developed need to not only prepare children for school but increase 
parental knowledge and gain their support by keeping in mind the cultural variations with respect to determining how children should develop and what skills they should acquire (Barbarin, McCandies, Early et al, 2006). For example, in one US study, Latinos looked for programs that provide multiple services while African Americans placed a greater emphasis on the idea of a partnership and the relationships they had with staff. In addition, cultural norms vary between Western and non-Western countries, indicating the need for flexibility so that children and their parents are not made to feel as if they must choose one way or the other (Prochner \& Cleghorn, 2005). Being forced to choose may not only confuse the child but create barriers to parent participation as the latter may feel uncomfortable with and suspicious of different methods of teaching; rather, a collaborative environment may allow for a smoother cultural transition for children from varied backgrounds in early years programs.

These findings have serious implication for ethnic minority/newcomer families. For one, early years programs need to consider how they can initiate and maintain relationships with these populations. Secondly, understanding the cultures and what the expectations are for preschoolers among the parents and adults from those cultures may help in determining where the children from other cultures stand with respect to the North American position on school readiness. As well, realizing that cultural and socio-economic background plays an important role will help educators better educate parents on what their children may need in order to improve the children's chances of succeeding in school environments that may be different from what they are used to. Parents tend to construct ideas of what they can or cannot do with respect to their children's education, and so enlightening parents on the important role they can play and teaching them how they can become (more) involved in their children's education would provide children with a stronger support network of people they may turn to for assistance (Hoover- 
Dempsey, Walker, Sandler, Whetsel, Green, Wilkins et al, 2005). Nurturing this relationship from an early age may help children adapt faster to their school environment. Golan \& Peterson (2002) suggested that some ways of encouraging involvement, especially for immigrant families, include addressing parents' direct needs; making personal connections; raising awareness and concern around student achievement and the need for parent involvement; demystifying the workings of the school system; suggesting concrete behaviours that parents may use to support their children's academic success; using methods proven to support learning and increase the likelihood that new behaviors be adopted; and creating a sense of community and peer support network that can exist outside of the class.

Community support may be even more important for families coming from a lower socio-economic background. One Canadian study found that school readiness, as measured by the Early Development Instrument (EDI), varied in relation to socioeconomic, health, and family structure variables (Janus \& Duku, 2007). More specifically, they found that children coming from families with lower SES were considered to be more at risk at time of school entry. In another study where EDI scores were analyzed, Lapointe, Ford, and Zumbo (2007) found that this lower income rate was associated with adults who did not speak/use an official language (English or French), had immigrant status, had less than a grade 9 education, and had lone-parent status. This is a strong indication that the environment in which children are raised has a strong influence on their school readiness. However, assuming that all children from lower SES backgrounds are at risk in all aspects of development may not be plausible. One study found that SES-EDI models strongly predict the vulnerability of children in the physical, cognitive, and communication domains more so than in social and emotional domains (Kershaw, Forer, Irwin, 
Hertzman, \& Lapointe , 2007). Despite this limitation, it is important to consider what supports are available to these families in order to counter these and other risk factors.

\subsection{What are we doing, why, who will it be for?}

The literature reviewed suggests that despite a lack of clarity regarding a definition for school readiness, early years programs are in fact beneficial to both children and parents and the gains made from participating in such programs, especially for immigrant families, cannot be ignored. As cited in the literature above (Hoover-Dempsey, Walker, Sandler, Whetsel, Green, Wilkins et al, 2005), parents' understanding of what they can do to help their children may be limited to what they have been previously taught. For immigrant parents, their knowledge of what their children can and should be able to do may differ from that of white Anglo-Canadians. In addition, immigrant parents who take part in the program may become aware of what they may or may not do in the schools and gain a support network to which they can turn in times of need. This may be useful in ensuring that they become active participants in their children's schooling as mentioned by Golan \& Peterson (2002), thereby increasing the chances that their children will be better prepared for school. Bernhard, Freire, Pacini-Ketchabaw, and Villanueva (1998) found that when a group of Latin-American parents were brought together with an expert to discuss issues and experiences they faced with respect to their children's schooling, parents found the group to be useful and were able to play a bigger role in their children's education as a result.

As indicated earlier, the purpose of this study is to examine the School Readiness program offered by the Ontario Early Years Centres in an attempt to assess the effectiveness of program delivery. Overall, the study will provide a critical assessment of an important 
educational service with an aim to assisting in improving the province's educational programming for young children. 


\section{Chapter 2: Methodology}

\subsection{Researcher's Characteristics: Personal Reflections}

For the past few years, I have been employed part-time by the OEYCs, in particular at the two ridings that are used in this study. My job involves entering program information (i.e. quantitative data on where and when the School Readiness program is offered and who participates) into a database system to assist the site supervisor in preparing quarterly reports for the government. Working with the data, which did not provide much if any qualitative information, I began wondering about the details-such as program delivery and whether there were any mechanisms for assessment - that were not evident in the numbers I was entering. I also have a strong personal interest in parent/child programming and have, over the past few years, developed a curiosity as regards how these programs are meeting the needs of the communities in which they are offered. Having recently had a child of my own, I was particularly interested in the School Readiness Program as now, more than ever, I have a vested interest in how well the program is doing. Furthermore, my formal training in the MA program in Early Childhood Studies at Ryerson University and my newly developed motherly instinct have confirmed for me just how significant a milestone starting school is in the life of not only the child but the parents as well. I was particularly concerned about how well immigrant children and families are being served by the School Readiness program because my family immigrated to Canada when I was a child and I have many extended family members and friends who are newcomers with young children and I am aware of the difficulties they face as they try to give their children the best start in life that they can In a discussion with the supervisor of the sites where I work, I was made aware of the fact that, up to that point, no formal assessment of the School Readiness program had been undertaken. At the time I was completing course work in 
my program and thinking about what topic I should focus on for my Major Research Paper. Armed with this bit of revelation from the site supervisor, I felt compelled-for all the reasons indicated above-to do my research paper on the School Readiness program.

My immediate goal was to learn more about how the School Readiness program is being delivered and since the Child Development Consultants are the ones who decide the how and what of the program, it was important for me to talk to them about their practice in order to get a full account of program goals and objectives and an indication of how successful they think the programs run have been. I realized that assessing the program through the lens of the CDCs was an important first step towards a comprehensive evaluation of the School Readiness program as without them the program currently does not exist in reality nor has any tangible form.

\subsection{The Qualitative Approach: Rationale}

A qualitative research approach is used as this type of research places value on the opinions of the participants (Bryman \& Teevan, 2005). This approach is particularly appropriate for this study as, going in, the researcher had no pre-existing categories or criteria identified by the OEYCs against which to compare the CDCs' practice and was unsure as to whether there was a set structure for delivering the program. So, rather than attempting to fit the study participants' responses into pre existing categories, the researcher allowed the assessment categories to emerge out of the interviews. This practice accords with the observations of Connolly (2001), who states that qualitative studies allow for participants to give their own responses to questions and explain themselves rather than be forced to choose an answer and provide any justifications. 
The qualitative approach used is based in the case study method. More specifically, a collective case study is used because, "multiple cases are described and compared to provide insight into an issue" (Creswell, 2005, p.439). A collective case study is employed-as opposed to, for example, an instrumental case study where one case is studied in order to provide insight into an issue/theme (Creswell, 2005)—as the nature of the assessment required accessing information that represents a range of program workers' perspectives on program delivery.

\subsection{Description of Sample}

Three Child Development Consultants who ran the School Readiness program in the past year in the two Toronto ridings chosen for the study were interviewed. Eligibility requirements for the study stipulated that those interviewed had to be current employees of the Ontario Early Years Centres and must have planned and delivered the School Readiness program. The reason for restricting those to be interviewed is that only those who have had some experience working with the materials and directly with the parents and children could provide real insight into and feedback about the program.

Among them, the CDCs had recently completed no fewer than six runs of the program between April and the end of August 2007. One of the CDCs had run the program three times during that period, while another had done two runs of the program and the other CDC had run it only once. The number of program runs allowed for a good assessment of variation across the sample and sufficient information to determine the details of the CDCs practice and their perspective on their own practice. Due to the qualitative nature of the study, non-random purposive sampling was preferred and used, meaning that specific people were asked to participate in the study and that "the researcher intentionally select[ed] individuals and sites to learn or understand the central phenomenon" (Creswell, 2005, p.204). One detail that emerged 
from the sampling was that each of the CDCs comes from a different ethnic background: Italian, Anglo-Canadian, and Hispanic. Also, it was noted that the two Toronto ridings used for this MRP each has a different participant demographic. Two of the CDCs, the ones with an Italian and a Hispanic background, work in the same riding where the community has a mix of people of European (for example, Italian and Romanian), Hispanic, Chinese, and Filipino descent. The Anglo-Canadian CDC works in the second riding and she noted that the families who participated in the program were also from a range of backgrounds: Somalian, African American, Vietnamese, Spanish, Portuguese, and Anglo-Canadian.

\subsection{Site and Interview Process}

At the time the interviews took place (September 2007), the Child Development Consultants who participated in the study had just delivered their most recent run of the School Readiness program to children expected to start school in September 2007. Hence, the interviews were conducted at a most opportune time: close enough to a program run such that the CDCs' memory of what transpired would still be fresh and vivid but with enough time between the end of the programs run and the interviews so that the CDCs had enough notice and time to reflect on what they did before sharing their experience. The interviews took the form of one-on-one exchanges between each CDC and the researcher and each interview too place in an office at the OEYCs site where that particular CDC works. Interview dates were set according to each CDC's availability in order to increase the participants' level of comfort with the process. Prior to beginning the interview, the researcher gave each $\mathrm{CDC}$ a consent form and carefully explained the nature and purpose of the study. Although the CDCs had agreed prior to the actual interview meetings to participate in the study, the researcher reminded them that they had the option of passing on being interviewed. None did. Each interview session lasted approximately thirty 
minutes. In the interviews, the CDCs were allowed to talk freely and encouraged to comment on all aspects of their program delivery and practice, including information that the researcher did not directly solicit. As well, the CDCs were asked to clarify and elaborate on their answers in order to provide concrete examples of their experience working with the materials they chose and with the families and children. The consent form and interview questions used in this study are provided in Appendix D and Appendix E respectively.

\subsection{Data Analysis: Theory and Process}

A grounded theory design informed the data analysis process in this study. Grounded theory designs are "systematic, qualitative procedures that researchers use to generate a general explanation that explains a process, action, or interaction among people" (Creswell, 2005, p.52). Procedures involved in a grounded theory design primarily include collecting interview data and then relating themes/categories of information and composing a figure/visual model in an explanatory fashion, thereby facilitating the use of the experiences of individuals in constructing research statements (Creswell, 2005). As there were no previous assessments/analyses of the School Readiness program to draw on, the interview data collected helped shape the researcher's understanding of the program currently in place. While there were specific questions that the researcher needed to ask and had prepared prior to the interviews so as to provide a framework and context for interviewing the CDCs, the researcher opted to use the semi-structured format for the interview sessions so that the CDCs were given the opportunity to help identify (through their responses) what questions would generate the best kind of information for the stated purposes of the study.

All taped interviews were transcribed to enable deeper analysis. To ensure anonymity, the real names of interviewees and other participants referenced have not been used; instead, 
they are each given an alias. The interview responses were reviewed and colour coded according to the sub-headings seen in the results section so as to pull out, organize and synthesize all relevant information provided from the CDCs' perspective to determine, among other considerations, how the school readiness program is run; how the OEYCs through their CDCs are preparing children for school; what positive outcomes the CDCs have observed; the challenges they had delivering the program; and whether or not program delivery was explicitly geared towards concerns and needs of immigrant/newcomer families. The responses of the participants are also used to form the basis for the recommendations provided at the end of the MRP.

\subsection{Strengths and Limitations}

With respect to the limitations of the study, as mentioned in Chapter One and again reiterated in the limitations section at the end of the MRP, this is not a full evaluation of the School Readiness program but rather a preliminary analysis effected through the perspective of the CDCs. A more comprehensive evaluation aimed at assessing program effectiveness and whether it is in fact meeting its goals is envisioned and recommended for the future. The strengths of the study are evident in it's:

\section{a) Credibility}

The program workers asked to participate in the study have had experience with the School Readiness program (planning and implementing) and are currently employees of the OEYC. This information was again confirmed before the time of interview with the supervisor of the site at which they work.

\section{b) Transferability}


The results of this study have high transferability. There are many child development programs being offered by other agencies and this study of the OEYC School Readiness program can help both the OEYCs and these other agencies undertake an internal assessment of their individual programs. In the specific case of the OEYCs, although program workers are currently at liberty to make their own decision about the details of delivering the School Readiness program, it is hoped that the recommendations provided in this study will enable the OEYCs to develop a more structured approach to program delivery, which would in turn allow for better internal as well as external assessment of program effectiveness.

\section{c) Dependability and Confirmability}

To ensure that the interpretation of results has not been biased by the researcher's views and prior knowledge of the sites, complete records have been kept of all phases of the research. All interviews were taped and later transcribed for analysis. To further guard against researcher bias, the researcher's supervisor reviewed the interviews and engaged in regular discussions with the researcher about the information gleaned from the interviewees, which both challenged and confirmed the interpretation of the findings.

benefits and challenges, what needs to be changed, what works in the material, what is being used to develop literacy, numeracy, and socio-emotional skills); b) comments made in regard to participation in the program, especially with respect to immigrant families. The information provided by the interviewees is discussed later on in this study in order to shed more light on whether or not the program is in fact meeting the needs of parents and children, especially for immigrant families, and whether the materials used develop more than just literacy and numeracy skills (i.e. socio-emotional); that is, whether there is an emphasis on socio-emotional development as well. 


\subsection{Validity and Reliability}

\section{a) Credibility}

The program workers asked to participate in the study have had experience with the School Readiness program (planning and implementing) and are currently employees of the OEYC. This information was again confirmed before the time of interview with the supervisor of the site at which they work.

\section{b) Transferability}

The results of this study have high transferability as there are many programs offered by other agencies that would benefit from this knowledge. The data gathered tries to assess not just the program being run by the OEYC, but who might benefit most from such programming. Although the sample size is small, it is hoped that a general consensus with respect to the research questions will arise. Although program workers may not view all situations in the same light, it is hoped that a trend may arise in order to draw some conclusions.

\section{c) Dependability and Confirmability}

To ensure reliability of the results, complete records have been kept of all phases of the research. All interviews were taped and later transcribed for analysis. To ensure that the researcher's bias (that school readiness programs are in fact useful and that immigrant parents would benefit most from such programs) does not compromise the study, an additional individual (i.e. the supervisor) has reviewed the interviews as well. 


\section{Chapter 3: Results}

Information gleaned from the interviews is organized according to the response provided to the research questions clearly identified below in order to synthesize the information gathered.

\subsection{How is the School Readiness program run by the Ontario Early Years?}

a) How, when, and where classes were held

There was no set structure, schedule, or objectives (as pertaining to school readiness competence in children) when the CDCs ran the School Readiness program. Each of the Child Development Consultants (CDC) prepared and conducted her own program according to what she thought was important. While one CDC held her program the week before school began, the other two CDCs held theirs before summer (during the period between April to June). In addition, the amount of time each $\mathrm{CDC}$ allocated to and way she ran the program differed. One CDC simultaneously ran two School Readiness program groups, with each running one day per week in a two-hour block over an eight week period. Another CDC ran three groups, with each group meeting for two hours each weekday for two weeks. A third CDC ran one School Readiness program group in the week prior to the start of school in September 2007. Her group met for an hour and a half each weekday. Table 1 below provides information regarding the three participants.

Table 1

CDCs and their School Readiness program

\begin{tabular}{|c|c|c|c|}
\hline & $\begin{array}{c}\text { \# of groups run in } \\
2007\end{array}$ & $\begin{array}{c}\text { When was program } \\
\text { held? }\end{array}$ & Location \\
\hline Lisa (Italian) & 3 & $\begin{array}{c}\text { May/June, 2 hours } \\
\text { every weekday for } \\
\text { two weeks }\end{array}$ & $\begin{array}{c}\text { School- classroom, } \\
\text { Portable, on a few } \\
\text { occasions during }\end{array}$ \\
\hline
\end{tabular}




\begin{tabular}{|c|c|c|c|}
\hline Jessica (Anglo- & 2 & $\begin{array}{c}\text { April and May, 2 } \\
\text { hours, once a week } \\
\text { for approx. 6-8 weeks }\end{array}$ & $\begin{array}{c}\text { School's lunch room, } \\
\text { unused kindergarten } \\
\text { classroom }\end{array}$ \\
\hline Mary (Hispanic) & 1 & $\begin{array}{c}\text { August, 1.5 hours, } \\
\text { every weekday for } \\
\text { one week }\end{array}$ & Library \\
\hline
\end{tabular}

All three CDCs did not run their programs out of the OEYCs. Although the OEYC is equipped for such programs, there are other programs already running in the centres that would not make it feasible to hold classes there especially for the sessions that ran every weekday at the same time. Rather, the CDCs ran their programs out of schools and in one case out of a library. Recruitment for the School Readiness program that ran out of the schools occurred in collaboration with the schools, as can be seen from the comment below:

So I thought to do it at 2 schools. I contacted the principal[s] and met with the principal[s] and negotiated some time with them. And they thought it was a great idea to hold it at their schools. So they helped promote it. They made a flyer. They put it out to all of their kindergarten registrations. And then we decided to do it for-I'm trying to remember how long - well it went from...one started at the end of April and one started in May. So once a week for about 6-8 weeks. [Jessica, p.2]

One CDC even mentioned the importance of the school's support:

Yes, I ran 3 school readiness programs and they were 2 weeks long about 2 hours in length. What was unique about the 3 programs was that I didn't run them here 
out of the OEYC. I actually went to the schools. And so that was the model. To run the school readiness programs in the school. And it required big commitments from the school since they had to provide me with the space and time and also help me with the recruitment of the families. [Lisa, p.2-3]

Lisa further explained that the flyer was distributed during a 'Welcome to Kindergarten' session held at the school and that was how families were recruited for her School Readiness Program:

Well it's the "Welcome to Kindergarten" the schools have now... [for] children registering for the fall.... They invite us-the Ontario Early Years [Centres] - to come out and talk to the parents... So I thought, let me have a flyer of school readiness and that's how I recruited all my families. So the flyer was ready and I talked to them about the program and I signed them up that evening. So that's how they found out. All the kids who attended my School Readiness program were all children going to school in September. [Lisa, p.4]

The third CDC said that she was unable to hold the school readiness program in a school since schools are closed during the summer and so she held her program in a library instead. In this case, it was the library that worked in collaboration with the CDC to promote the program and gather participants:

I ran the program in the library. And...the library gave me their auditorium space. So I brought in all the materials, everything that I needed-everything that Ifelt was needed to run a school readiness program for 5 days... 
...I sent out a flyer to the libraries. We [the OEYC] also have a good relationship with that library and I know the space so we sent out a flyer. They did advertising for us. We sent it to public health. We sent it to other programs we're affiliated with and we also just, you know [did] door to door type of canvassing as well...

... this wasn't done through the schools... Because it was the last week of August the schools weren't really working; they weren't really open. [Mary, pp.1-2]

As a result of the outreach initiatives, program enrollment ranged from the lowest of 4 children in one group to the highest of 12 children in three other groups. Two of Lisa's three groups had 12 children enrolled and her third group had 4 children. Jessica had 6 children enrolled in one group and 8 in her other group. Mary had 12 children enrolled in her School Readiness program.

\section{b) Program's target: Children versus Parents}

Two of the three CDCs provided programs to children with the specific aim of teaching them what a typical day in Kindergarten would be like in September while also providing parents with information such as what they needed to know with respect to their children's development as well as information on school environment (i.e. schedules, snacks, and expectations such as calling in when a child is sick). Their main aim was to prepare children for school and give them the tools they need to better adapt to their new school environment:

...the routine was really important and the children had to follow the routine. But also being in the school, I found that they were starting to get comfortable. And even walking down that hall, and using the washroom and seeing where the principal's office was. Going to the kindergarten class so that they are a little 
less frightened in September. That's what we're hoping... So the kids had sort of like a kindergarten structure. [Lisa, p.5]

Although introducing children to a typical day in Kindergarten was still Mary's main aim in her School Readiness program, in terms of communicating information to parents, she gave an explanation as to how this was done. She communicated with the parents during break time. In addition, she also gave the parents information such as handouts on what they could do to prepare their children for school that they were able to take home with them:

My goal was to introduce what a typical day would look like in a JK program. And I gave information out. I always had some type of information, some type of topic that I wanted to speak about. But it was very informal. So when the children had snack, this gave me the opportunity to hand out my flyer to the parents and this is when we had our talk. And parents were able to ask me questions. We had a lot of dialogue happening in terms of having parents network in terms of different schools in the area and networking between the families. There was a social time for the parent, social time for the child and I also gave out information. And in terms of the child, it gave them some information, [so] they would know what to expect. So coming from me, when they went to their JK room, they knew they would have a teacher they would have to put their hands up and wait in line, they needed to take care of their own needs. Play age appropriately, play socially well with other children. So it was two fold. So I did have some time [with] the families... [Mary, p.3] 
One CDC felt that it was more important to give the parents information rather than show the children what a typical day of kindergarten would be like and so her program was targeted towards parents and giving them information they would need to help their children prepare for school:

I think it has a little bit to do with the child but really it has to do with the parent. That the parent is involved in how the child is learning. If the parent is involved, the child I think will do better in school in the long run so if they're not coming to an early years, I try to convince them to come to an early years so that they get the... sense of- ok circle- the teacher means to come and sit. Fold up my little legs, things like that. I think my main goal is to hook the parents into seeing where their child is developing in school to get them excited about this aspect of the child's life and to know that it makes a difference... [Jessica, p.4]

c) How the program was run: a typical day

Two of the CDCs, Lisa and Mary, said they provided activities that centre on what could occur during a child's daily experience in Kindergarten. Examples of what a typical day in the program was like are provided in the comments below:

We always had a welcome when the children came in. They [had to find] their name tag. Some weren't able to identify their name so we did that with the help of the caregiver they were with. They came in [and we] did our morning or good afternoon song. We did a little talk and then the kids were introduced to what they would do next, to whatever craft I had available. So I would explain to them and give them some directions and the parents would help them. The kids would work 
on the crafts. Sometimes we did planting, did their letters, beading necklaces. They did a lot of different things. Sometimes with glue, sometimes with scissors. They were introduced to a lot of different [medias] of doing things and some children were never introduced to things like that and the parents would assist them. So they'd have about a half hour there; and then sometimes we'd have opportunities to go into the schools so I had gym time planned or outdoor time planned, [library]... So the kids were introduced to books and parents would be encouraged to read to their kids and a lot of that went on.... Oh, recipe for play dough was another thing that we did in the group. [We did] play dough together, 'cause some parents thought play dough making was really hard and when it was seen that it was easy and how long their child spent at the table, they liked that idea. They never thought of doing it at home... and the other thing they learned was their name. How to recognize their name 'cause it's really important. [Lisa, pp. 4-5]

Mary provided a more detailed outline of what her School Readiness program entailed. As mentioned previously, her goal was to show what a typical day in Kindergarten would be like and so the format of her class reflected her objective. In addition, because parents were encouraged to play with their children and be involved in their learning, many opportunities for parents to learn what their children would be doing once they start Kindergarten presented themselves because of the format of the group sessions:

When they came in they had a specific location where they put their bag, or their jacket or something that they brought with them. We would have a welcome type of circle and I would go through the class rules and schedule for the day. And it 
was also posted...my program was specific so that I would explain the different areas of the room and I would tell the children it was their work time and that the parents had to follow the children to their work time and then I would turn the lights off twice during that program so that children and parents had the opportunity to go to a different work station. So during that time they went to at least 3 stations. [Mary, pp.2-3]

Jessica, who focused her program on the parents, did so because she felt that it was the parents who needed to be informed of what to expect. She used her time to give the parents various types of information such a developmental screening tools and answer questions they had about their children's transition to school. The description she gave of the way she ran the program provides an example of one such question the parents had and her response to it: ... they always had play dough. Just to give out one activity per week so because I didn't have a separate room and I had the parents with me all the time so I had to kind of make due and I was all by myself. [Jessica, p. 5]

It was mostly with the parents I was talking to. I mean I had activities with the children there to match up with what I was talking about...I talked a lot about the social aspect-the socio-emotional aspect of child development. That's where we have to really look at our children. So I broke it down into little things, little activities. And I talked about that for quite a few of the weeks and some of the parents wanted to talk to me...[for example,]do they have to know their abc's and [do] they have to count. Then I brought out, I think it was something from the school that they just need to be ready to learn... So I say what you need to work 
on-when we were talking and the parents asked that question-what you need to work on is more the sounds of our alphabet rather than the abc's and that they can sing the song. So I said as you're going out walking, read the signs as you're walking. So 'stop'. Point out the 's'. the sound 'ssstop'. Or 'bird'- b-b-bird. So I gave them suggestions and there was a handout that I gave them [Jessica, p.6]

\section{c) Program materials used}

Program materials consisted of various activities for the children such as play dough, games, toys, and books. In terms of the parents, the types of information given to them pertained to what they needed to know about the schools. For example, Mary provided a handout to the parents that she had put together after looking at various websites and the Toronto District School Board's recommendations for getting ready for school. Jessica, whose main focus is imparting knowledge to the parents, gave the parents various handouts not provided to the researcher as she was unable to find them; however she provided a verbal description of one handout. The handout gave parents suggestions about what they could do with their children in order to prepare them for learning. As well, she helped the parents complete various developmental screening tests such as the Nippissing Checklist so that the parents could see where their children might be lagging behind and then later pointed the parents to the appropriate resources and services such as speech and language therapy. In Lisa's case, she used ideas and materials from other programs she ran in order to develop her School Readiness program: 
I think some of it came from programs here. I do a circle friends workshop as well.... We do a lot of singing and things like that so I had the program already ready. So a lot of the props were ready for me so I used that. And then other things I did was talk to the teachers and got some information from them. And so I got stuff, I guess. We have a whole closet here full of materials.... I opened it up and saw beads and thought, 'Oh, we can make necklaces.' [Lisa, p.6]

3.2 To what extent do the Ontario Early Years prepare children for school readiness?

a) Cognitive development (literacy and numeracy)

The focus of the programs, according to the CDCs, was not to make children literate in the sense that that they could read and write by the end of the program but to develop certain basic skills so that they would be ready to learn by the time they began kindergarten. The CDCs acknowledged that each child comes with different skills depending on how much they have already been exposed to. The CDC's aim was not to have the children reading and writing but to help them recognize certain letters and numbers. One example of how this was done is demonstrated in Lisa's response:

[The children were asked to] participate in circle [and] to find their names. That was the first thing they did. And I remember... that most of the kids didn't know their name, couldn't find-identify their name. And what I did was I got them to choose a sticker that they really liked and put it on the outside of their name tag so it was on the plastic thing so they could see their name. So that helped. It was like a cue in helping them find their name. And then we did some songs. And I had some actual things again like props and the materials here and there. So it was 
nice to have lots of stuff. And I had an alphabet. It's actually a sensory alphabet so it's sort of like a beanbag and it has an A and then it has things in the bean bag that start with the letter A so like 'apple' and the kids find it. And so we did things like 'ah ah ah'. So we did the different sounds we did the phonics... I always said to parents if they're not ready to write it, it's ok. And even if they scribble their name, that's just the beginning of it- of writing... Sometimes we had to draw a line from [one point on the page to another point] So parents could see that I wasn't focusing on individual letters but I was focusing on straight lines, curvy lines circles, bumps, and all that is really important because if they can do that then they can put letters together. But when we give them the letter, sometimes it's too hard for the child[ren]. [Lisa, p.6]

In addition, learning methods did not always focus on keeping the children at their desks. Methods for learning included singing songs and other forms of play. As a result, as one CDC explained,

[The children] were able to have conversations. They were able to express themselves a little bit more. There were books available [and] puppets. We had like a circle time, magazines, things like that. In terms of numeracy, we talked about counting, we talked about some print awareness. [Mary, p.4]

In Jessica's case, she made sure to read to the children at the end of each session after she was done working with the parents. To promote cognitive development, she gave the parents examples of how they could incorporate different activities into their children's everyday routine. 
So, literacy was more on reading a story with them every week. And then talking about [different things]-just on the way home... [Or] making a shopping list when they went shopping-anything to promote them thinking about the words around their environment. [With respect to] numbers- we talked about going down the stairs. Counting-I said you might feel like a broken record, you're talking all the time but this helps your child. When you're going down the stairs, you know count '1,2,3,4'. I said you don't have to count up to 100. Just keep counting '1.2.3.4.5; 1.2.3.4.5' they get that concept well, [and] then the other concepts will come... So we brought in some kind of counting game that the parents could do at home also... It was easy and I didn't bring in sheets of math or anything like that. But the parents sometimes want that hard paper to say my child can do this and I said it's more [about] sorting socks when you're doing the laundry. I said you're teaching [a skill such as] whose sock [does this belong to]the baby's sock is little. Does it match with daddy's socks? No. ok let's match. So [doing] matching games at home. [Or] you're cutting a pizza. [So you might tell your child,] well the pizza is round... talk about the whole and then we cut it in half and then we cut it again. Just labeling those cuts. They don't have to know that one half plus one half equals a whole but it's just labeling it. [Jessica, p.7]

b) Socio-emotional development

All three CDCs agreed that it is more important for children to be socio-emotionally rather than cognitively ready for school. They all felt that despite being cognitively ready, if a child were not socially and emotionally ready, then s/he would be unable to function in and adapt to the new school environment: 
If a child can socially and emotionally be prepared then the learning just happens automatically, but if they're not socially and emotionally ready for school... then it's harder to teach them 'cause they're so worried about all the other stuff in their life that it just doesn't happen. So if a child is always crying or a child won't speak-you know then they're not quite ready. They can't tell a teacher that I need to go to the washroom. They can't share. All of that and they're getting into trouble all the time because that socio-emotional maturity isn't ready. Then teaching them is hard because they are always in trouble. [Jessica, p.6]

I would say the social aspect of it. Because we know that if the child does not feel secure, does not feel confident, does not feel cared for, the child is not going to learn. So you can put as many flashcards in front of them, as many letters, colors, any type of cognitive skills in front of them but if he's not confident, he's not going to be ready to learn and accept those skills. [Mary, p.4]

The School Readiness program executed by the CDCs-especially in the case of Lisa and Mary - was geared toward fostering learning through play so that children could develop their cognitive skills as well as the social skills necessary for them to succeed in school:

[What's important is] just getting that familiarity of leaving their parents, being in a classroom environment and [the] certain expectations that are brought out in JK. So even if the child is getting used to going to a play group, once they get to $J K$ and they have to sit for a certain amount of time, they have to put their hand up, they have to take care of their own needs-that's still something new for a lot 
of children. [Children need to become] familiar with it a little more so when they start school the following week, it's something more familiar [and] it's not such a big transition for them. [Mary, p.4]

In Jessica's case, although she did not provide a program specifically for children, she did describe one instance where she was able to teach the parents and make them more aware about the importance of developing their children's social skills:

I had an experience where I had a puzzle where they could put two pieces together like an apple and the letter A. And the children had these on the floor behind me and I was talking to the parents... These boys were all fighting over the pieces! Then the principal walked in and we all [felt that] maybe they weren't quite ready to play with the puzzle, so [we should] tidy it up. So then the principal and some of the parents got up and tidied up and then they [the children] all had to go to the washroom. So when they came back it was a good chance to do a game where we took turns. You know my turn, your turn. So we took turns labeling it. So the parents were going to sit back and I said bring your chair up we're all going to sit in circle together and we're all going to help our children take turns. And they were all so surprised that their child couldn't take a turn. [Jessica, p.5]

In one of her groups, Lisa used a situation where some of the children had forgotten to bring their snacks as an opportunity for the children to learn to help each other out: 
[The] children were responsible [for bringing] a healthy snack. I did that because in school that's what they have to do. It's an expectation-they have to bring a snack. They learned a lot from each other and [about] some of the healthy snacks so I would point [and say], 'Oh look at that. So and so has an apple." Or, 'He has apple juice to drink or water'. Then I would talk about the different containers, [such as] if it was a plastic water thing [bottle] that they could reuse... And the parents would pick up on that... On my first day over here at [school's name], there was a grandma who came and she brought so much snack and some of the children didn't bring a snack, they [had forgotten]. And I didn't have a backup snack, and the grandma looked and said-well she spoke Italianand she said, 'They didn't bring a snack?' And I said, 'No.'. [So] she said 'Ok everybody, have a piece'. She had crackers; she had fruit- enough for those who didn't bring a snack. Well then the next day, the kids came with a snack and the kids who forgot that day brought their snacks. And I had two new kids who were starting and those children shared their snacks [with them] and I thought that it was a really nice thing. [Lisa, p.7]

In other instances, there were situations were the CDC would deliberately not provide enough materials so that the children had to learn how to work together: If they wanted a toy, they had to wait for it sometimes. Or they could ask their friend for it. So there were times that things were set up. Other times the craft area was set up in that [I purposely] didn't put out enough scissors for that day because I wanted them to ask or wait for the glue to come their way. So I thought that was really important that kids figure that problem out. So they had lots of 
opportunities to practice being in group and also just being with another friend to know how to play and ask for things. [Lisa, p.7]

c) Measuring outcomes

Mary and Lisa discussed how they were able to assess the effectiveness of the delivery of their program. Lisa had two ways of evaluating the success of her group. Of the three CDCs, she was the only one who had the teachers of the kindergarten classes where the children went after they participated in the program complete a survey. The teachers were given a survey in September shortly after the children entered kindergarten. On the survey, the teachers were asked questions about the children, such as how capable each child was at doing various tasks. In addition, both Mary and Lisa discussed how the children in their groups changed from the first day they attended the program to the last. Their comments below give an indication of come of the changes they observed:

Some kids were clinging to their parents and wouldn't let go and didn't want to come to circle, and I said to the parents 'It's ok, they'll come.' And usually they came by the $3^{\text {rd }}$ class. They started coming closer to me. Sometimes I invited the parent to sit in circle so they'd come closer... I found that by the $2^{\text {nd }}$ week the kids were already participating. So I say one benefit of doing it in 2 weeks is you can see the change. Had I only done the first week, I wouldn't have seen the changes... I saw some kids who weren't able to sit-[at the end] they were sitting. Sometimes I provided a chair for the kids. So I looked at why they weren't sitting and tried to accommodate that. And also you know [I did] things that were active. 
Some of the kids couldn't sit still for long so we did active things like getting up and I kept my circle to about 15-20 minutes [Lisa, p.10]

On the first day it was directed by me. So I directed every stage of the day. Every time that we had to change from one routine to the next, it was led by me. By the fifth day, the children became a lot more familiar with what was expected of them. The children helped each other remember what was expected of them. And they just followed the routine so that they knew what to expect next. And we had a schedule on the board. They could just visually look at it and know what was going to happen next. So if I turned the light off they knew it was time to tidy up and go to the next station. After snack time they knew to tidy up and that we were going to sit now for a circle. So they knew what was expected. So by the fifth day I pulled away. Well I pulled away every day, but by the fifth day they knew already. [Mary, p.4]

3.3 Was there, from the perspective of the CDCs, any indication of a difference between those who participated versus those who did not?

When asked whether they thought there is a difference between children who attended the program versus those who did not, all the CDCs agreed that there are some differences such as allowing parents to see where their children are at and what skills they-the parents-need to help their children develop and learn what is expected of them. Lisa felt that those families or children who participate in the program are at an advantage. Below is an example of how Lisa provided guidance to one parent, supporting the CDC's claim that parents benefit from participating in the program: 
I spoke to a mom a couple weeks ago and she said, 'My child doesn't dress herself. She's going to kindergarten'... So she said [her child was not] dressing herself and [was not eating] by herself and [the mother was] having anxiety because her daughter [was] starting JK. And I said we needed to start practicing. It was not too late. [I told the parent that she needed to get her daughter] to do things on her own. And she was feeling a little overwhelmed because now she's not going to be there for her daughter and [she was worried as to whether she] will be able to eat, or will she [be able to] eat on her own and I said, 'usually children will find a way, if they are hungry they will find a way to eat' because the teacher is most certainly not going to sit there and feed her daughter. But there's things that she can do now to help her prepare like maybe choosing her [daughter's] clothes and getting her to undress [herself] and help her [get dressed such as] talking [to her daughter] about where the label goes. And [to] make it easy like no buckles you know since she's used to mom doing everything for her... I said to give her snacks [at home] that you would prepare for school. Like it could be a sandwich or fruit and give her things that she likes [to eat]. Things that are healthy but things she likes. And start by taking a lunch bag or whatever she would be taking to school and do it at home. Say, 'Here's your snack' and get her to unzip it or Velcro it. Whatever it is, but get her to take it out of her bag [by herself]. So I think that the parents who attended the school readiness program benefitted because they could learn from each other and got tips... [Lisa, 9] 
Jessica felt it was important in the sense that children who are exposed to more would be more adaptable to the change. She commented that:

Children are resilient. You know, maybe they're [the parents and their children] already [attending some] early years [programs]... We just know that-[based on] our education- that if the child has lots of different experiences that it'll make a difference when they go to school. [Jessica, pp.8-9]

Hence, she suggested that it may not necessarily be the School Readiness program that is making the difference, but the fact that parents may already be bringing their children to other programs that teach the same skills and develop similar awareness. The fact that families may already be attending other programs for their children may impact on the effectiveness of the school readiness program for the children in those families.

When asked if this program should become compulsory, only Lisa felt that it was a good idea. Her reasons for why she thought so are given in the comments below:

I'd like to see that because I don't know how long ago the 'Welcome to Kindergarten' started. Maybe 4 years and it's a fairly new program and the school gives them a bag of all these wonderful resources because they want to capture them in early and get kids exposed to all these different things. But also in talking to all the kindergarten teachers, they gave me feedback saying this is what kids need because they're finding they have difficulties... this program was helpful because sometimes they say they don't even know how to use scissors, or what to do with glue or simple things like that so they were exposed to it in the 'school readiness program'... So in an extension to 'welcome to kindergarten', 
[we need to show them] how we can use [the things in] that bag. I mean there are 4 stations and they are given 20 min thing and they go from one area to the next to use these materials but I think it would be an extension on that to learn it in the school readiness program...Because there were comments, like I said earlier, that parent said 'I thought it was taboo to give them scissors'. And some of the parents didn't used the bag even after, didn't know how to use it so I think spending more time with the families and saying it's ok. [Lisa, pp13-14]

Jessica and Mary did not feel that the program needs to be mandatory. While Mary felt that some kind of program might be useful, Jessica reiterated the fact that a school readiness program is to impart knowledge and skills and so she feels that to make it compulsory for all parents and children is unnecessary:

I don't know if I can say mandatory. But I know as someone who's in the ECE [Early Childhood Education] field and working with children and knowing the stresses it gives child and parent, I would highly recommend some kind of a school readiness program in the school. Not like with the OEYC. It could be a program [run collaboratively with the OEYC or other agencies] but in the school that the child is going to attend. [Mary, p.6]

No. I'd say no. I know that's personal. Because I think some children are ready for school. Some parents already know that information. To make it mandatory-I don't know whether that's necessary. [Jessica, p.12]

3.4 What are the positives outcomes and challenges faced while conducting the program?

a) Positive outcomes 
One positive outcome that emerged out of the program was that different community agencies such as the libraries and the schools partnered with the Ontario Early Years Centres to offer the school readiness program. In addition, parents felt comfortable enough to ask questions of the CDCs and learned to use some of the resources in their community, such as the libraries, as a result of attending the program. In both Lisa's and Jessica's groups, because they were held in schools, the principals went in and visited the groups. Lisa's groups were able to visit the Kindergarten classroom and the parents also got to meet the teacher.

You know when issues arise they [principals] make decisions, so they also came and introduced themselves and invited the parents. You know they [the principals] said to look out for meeting dates and they were given the information. So I thought this is really good, that the parents benefit. They're [the parents] already feeling part of the community and that I think is really important. It sends a message that my child is a part of this school, I need to get involved; I need to take part in this. [Lisa, p.10]

Meeting the teachers and principals gave the provides parents an opportunity to get to know those with whom they would be in contact when their children began school.. Also, the parents were encouraged to participate in their children's life at school by ask the teachers and principals questions and not binge afraid of exercising their rights. For example, Jessica dedicated a part of her program to informing the parents of the steps involved should they wish to see something in their children's Ontario Student Record (OSR).

Well I always brought a report card in from the school and I would show them the OSR file and I would talk about the school stuff also in one of the little workshops. 
So talk about that they would be getting a report card. What's in it. And then there's the interview-you should go to the interview and whether or not the teacher says no you don't have to go, you should. Even if it's just for a few minutes and say, I know you said I didn't have to come; my child's doing fine but pop in and say I just wanted to pop in to say thank you. Or just to see how things are going. Is there anything else I can do? Just to have that rapport going with the teacher... So I would show them the report card. And the OSR file and what's in it. And they have a right to see what's in the file. And if-well you can't just demand to walk in the principal's office and demand to see it. There's a process. And I would talk to them about the process. You need to inform the principal that you'd like to see it in writing. And then you make an appointment and you go in... [Jessica, p.11]

The parts of the program that focused on the children were also considered to have positive outcomes, as indicated in the comments below:

It wasn't always their name that they had to learn. Sitting is important, putting your hand up, knowing what to do when you're in the washroom. You know not just sitting there and not knowing what to do. Giving your child those skills are really important... The learning will come academically but if they're able to socialize and be socialized with other kids and groups, I think that's really important. And parents could see that. [Lisa, p.13] 
One of the positive things, the child learned certain expectations- putting their hand up, socializing amongst a group, peer interaction, helping each other, taking care of their own needs. [Mary, p.6]

A third positive outcome was the bonding and learning that takes place between the parents and their children. Many parents were not aware of the various activities they could do with their children. In addition, as a result of participating in the School Readiness program, parents were able to expand their support network through making friends with other parents and finding out about child care resources:

One mom was saying it was taboo in her culture to give scissors because they though scissors are dangerous and [that it is] not [good] to give [children] scissors. That's what they were always told. And she said now you taught me I can give scissors. [But] it's got to be the proper scissors. Not adult scissors. So they learned that. [Lisa, p.5]

You know I think seeing the parents when I'd be talking about a certain thing, [for example, on] how to hold a pencil. [You could see] light bulbs going off in their heads thinking 'oh I don't think I've ever given my child a pencil'. They wouldn't say it out loud, but you could see it in their face. [Jessica, p.9]

The parents were- the first week was really quiet-and the parents were listening. And you know doing everything. By the second week they were actually talking to each other. I thought that was a really neat thing because they're part of that community and they're going to see each other. And they need that support. [Lisa, p.7] 


\section{b) Challenges}

One of the biggest challenges Lisa faced was finding space to run the program, especially given her group size. One of her groups was placed in a small room, while another was housed in a portable:

Sometimes the space was small. Like in one of the schools they gave me a small room and I had 12 kids and 12 parents... and also the last school I was in put us in a portable. And I had no idea the portable was going to be so hot and this was in June so I would say that was the challenging part. [Lisa, p.10]

In Jessica's situation, not being in a proper Kindergarten classroom posed its own problems. In addition, one of her groups was held in the lunch room. She identified problems such as tables being too big for the children to the echo in the room:

The tables weren't the right size and we were always worried about that echo in the room also; and it was just challenging to be there the whole time and to keep everybody focused on an activity when we had the children because they didn't have play centres. And I did it in the classroom. Even in the kindergarten class it wasn't really set up for me to do it. If you have the [play] centres where the parents can move and you talked about different centres and they're making a plan, that seemed to work really well when I did it-not in a kindergarten classroom but in the early years room at a school. We just all sat down together as an opening circle because that's what happens in a kindergarten classroom, and then I would say all the different activities we had out at the tables; and I would say to the mom and child or dad and child, 'Think about the activities you 
would like to go to first and you'll see a number and that's how many can sit at that table:' And so I'd go around the room [and say], 'Ok, Julia and Hannah, which activity do you plan to do first?' and they'd say it and they'd go and do it. [Jessica, p.9]

Jessica also mentioned the language barriers that sometimes became an issue, especially with newcomer families. She attempted to solve the problem in part by asking the parents to let her know when they encountered a language/communication problem:

[With]English not being the first language[for some of the families] it was a little bit of a challenge so I always try and say to them at the beginning, If I go too fast, tell me' because I don't realize with English being my first language how fast I can get going [Jessica, p.9]

For Mary, another challenge was the behavior of some of the parents. She feels that those parents, although they had good intentions, had the potential to impact negatively on their children:

I guess a major challenge would be the parent and child interactions. Children definitely act differently among their parents than if they were left alone. And parents want their child to perform so well that they sometimes hinder that development or airway of learning so that would be a huge boundary I guess. [Mary, p.6]

What made working with the parents even harder was the fact that the CDCs had very little to no assistance. All the CDCs felt that this was a major challenge. Jessica's comments sum up the feelings of all the CDCs: 
Not being in a kindergarten classroom made it hard and being by myself [to run the program]-trying to occupy the children doing the activity, then focusing long enough on the activity and then trying to give parents information about the child's development [simultaneously]. So it was always back and forth. [Jessica, p.9]

At the other schools, it was only me. The parents were there in all three of my programs but I just couldn't stretch myself to, you know, talk to everybody. [Lisa, p.3]

In one of Lisa's groups, however, she was able to recruit three grade7 and 8 students. She felt this greatly improved the group experience as children were able to get one-on-one time-if not with her then with one of the student assistants. The student assistants helped with various tasks such as setting up work and play stations, lining up the children, and doing different activities with them. Instead of having to do all the teaching/learning activities by herself, Lisa was able to pass on some of these responsibilities to her assistants and found that the children felt comfortable interacting with and learning from the older students:

They helped with simple things like lining the kids up, [and] making sure the kids, when we had to go to the washroom, would wash [their] hands. They'd assist with giving them paper towels. When it was free play time, they would play with the kids [and] get the kids introduced to things like puzzles. [The grade 7 and 8 students used] whatever toys were available, helping the children, [and] having fun with them. And I found that when we were outside during recess time, the kids 
would just gravitate to the older kids and they'd play ball and they'd stick together and it was a really nice thing to see. [Lisa, p.3]

\subsection{Implications for immigrant families?}

It is important to note that the CDCs (perhaps because the Ontario Early Years Centres do not collect information on the racial/ethnic background and the socio-economic status of participants or whether or not they are newcomers) did not allow the fact that they had a diverse group of participants to impact significantly (if at all) on how they delivered the School Readiness program - this despite, as is mentioned in the literature review, the Ontario Early Years Centres' School readiness program is meant to be a universal and has a clear mandate to serve the needs of a diverse population. When asked to describe in more detail the makeup of the participants, the CDCs were able to shed some light on the ethnicities of the families who participated, although curiously they seemed to identify only those families and children from non-white Anglo backgrounds as "immigrants," which in itself is no indication of whether these families are newcomers or not:

We have immigrant families coming but we don't differentiate amongst immigrants or socio economic status. Our families come from everywhere. For example, we have Italian families, Chinese, Vietnamese. We have some Filipino families, some people from Romania. So anyone can come to this program. We have young and old parents, grandpas, dad's come, [and] moms. We also have caregivers who are homecare providers and who take care of children in their home and bring them [Lisa, p.2] 
The demographic at [this riding] is a variety of cultures and new immigrants. Each of the areas [where the program is run] has a different demographic and that's the problem. In some areas it's more the Jamaican culture or Somalian, Vietnamese, Spanish, Portuguese, Canadian. There is a variety at each site. [Jessica, p.3]

In my program, they range from families who are very needy, who are newcomers to the country, moms who are on social assistance all the way up to parents who are very highly educated and would be very well read in terms of child development and what to expect. So there a big range...I've come into contact with a lot of newcomers. A lot of Hispanic families that I guess easily approach me because I speak the language. [Mary, p.1]

As the CDCs were not able to provide specific information regarding what percentage of program participants were newcomers, this section will reflect on what the CDCs felt could be some of benefits as well as the challenges for newcomer families participating in school readiness programs such as the one they offer.

The CDCs felt that the School Readiness program can provide newcomer parents and caregivers with important information about how the education system works here in Ontario. Lisa found that many parents did not even know when the school year begins. As well, the CDCs felt that newcomer families (i.e. parents/caregivers) who participate in the program have ample opportunity to ask questions about a range of things that affect their children:.

I know immigrant families would gain a lot of information and because the size was a lot smaller and it was more [intimate], they could ask questions and 
parents could find out things. You know, about school and how it runs and the times. Like some of the families didn't even know when the school started. They could get all that information eventually when they met the kindergarten teacher and all that. [But]I found that the parents who attended had the benefit of finding out things about the school. [Lisa, p.11]

Jessica found that many parents use their own school experience to determine what their child's might be. So she felt that providing support and guidance is essential in helping parents, especially those who had their early education in places other than Canada, understand that their experiences may not be an accurate reflection of the education system and learning environment in Canada:

There's a fear of-especially for newcomers I find and maybe Canadians too-of the expert and you can't challenge her. Or the principal...You fall automatically into that trap of 'Oh I remember back when I was growing up, it's all the same'. So you categorize all these principals and teachers as all the same. [Jessica, p.11]

I think it really helps them [newcomers] to understand our school system [and] what's expected of their child. I mean every school in every country is different. They become familiar with the school system here. They try to help their child as much as possible. Just giving them a little bit of information is a step. [Mary, p.7]

The problems newcomers encounter because in many cases they are not familiar with the school system is compounded when they have weak English language skills: 
I would say language is a definite barrier. Secondly, I guess it would be different expectations-school expectations, curriculum expectations. Just the fact that their child is leaving them [is hard]. Because they're new to the country, they may not feel as secure as you know someone who's been in the community for 10-15 years, knows the principal or possibly knows the schools or have neighbours who have gone to that school. It's the unfamiliarity. [Mary, p.7]

The CDCs identified another benefit to newcomer families with poor English language communication skills who participated in the program: they were able to get assistance from English-speaking participants:

I had people in the groups who didn't speak English and parents could translate amongst each other; and you know they had some understanding of English but didn't really feel comfortable talking. They could talk amongst each other and get information that way. So they benefitted from coming. [Lisa, p.11]

Jessica also encouraged more interaction between parents regardless of their immigration status as she felt that such interactions would help the parents in not only improving their bond with their children but also help the children adapt to change. She stressed, as did all the other CDCs, that the program was not all about learning literacy and numeracy skills, which may happen early for the children of newcomer parents due to the emphasis placed on acquiring those skills in some countries, but about developing the children's social skills:

I think sometimes we overwhelm parent with [the entire] educational component.

If we can kind of try to convince parents to spend time with their child [and] interact with their child, I think that'll make the biggest difference with[the 
children] being ready for school. It isn't anything really. I mean if we wanted to teach something, that would be the thing we want to teach rather than any of the other things because then we could talk about fine motor skills, or turn taking. But if the parents are really involved with their child, they'll be doing some of that automatically. [Jessica, p.13]

Lastly, Mary discussed the isolation that newcomers to the country often face. With language barriers and no support systems, getting these families involved in programs such as the School Readiness program can prove difficult unless service providers are able to communicate with these families in the mother tongues:

I don't know how but more advertising. I don't know how we can find whoever's going to start JK [Junior Kindergarten]. You know some kind of a system where we know what child's going to start early enough in the school year that we can call back these parents and invite them to a program. Tell them that it's free... Just having them know about a program that's going to help their child get ready for school. I think the part is not knowing, especially for newcomers. You're very isolated. You don't have a lot of language. You may not have the language to communicate. You don't know people in the area or very limited people. So it's the knowing. Knowing what's available for them out there and their child who's going to start school. [Mary, p.8] 


\section{Chapter 4: Discussion}

What became apparent while conducting the interviews is that there is no set program for school readiness in the OEY. CDCs created their programs based on what they felt were important, making it difficult to evaluate the School Readiness program overall. The CDCs held their programs at different times of the year as well and targeted different groups (i.e. child focused program versus a parent focused program). For example, as indicated earlier, Jessica fúcused her program more on the parents as opposed to Lisa's and Mary's focus on the children. This raises the question of whether this inconsistency exists in all other ridings and community agencies that run the program. In addition, except in the case of one CDC, no follow up methods on the children were employed in order to assess the effectiveness of their programs. As a result, suggestions that will be offered for best practice will be made based only on the information provided in the interviews done with the CDCs for this study.

Because so much of the information gleaned was very valuable, only aspects of the school readiness program will be discussed as well as reviewed with respect to the literature in this section. Recommendations made by the researcher will be provided in response to the findings at the end of the discussion.

\subsection{How is the School Readiness program run by the Ontario Early Years?}

There was no set standards by which the School Readiness Program was run.

Each of the CDCs was responsible for creating her own program and holding it according to her own schedule or when she feels it is appropriate to hold the program. Hence, there was no real consensus among the CDCs on what might constitute a program of best practice. Because there appeared to be no formal understanding of what school readiness was, each CDC created a 
program that was based on their own experience and understanding of the term. However, all three CDCs agreed that socio-emotional competence was an integral part of school readiness even more so than literacy and numeracy. While Mary felt it made more sense to hold the program right before school began, Lisa and Jessica felt it was more appropriate to hold it around the time 'Welcome to Kindergarten' is held at the schools for the incoming children. One justification for holding it earlier was that it would help the children and parents see what needed to be worked on and so families would have the summer to improve those skills. The comments below reflect these opposing viewpoints held by the CDCs:

Back to February-offering maybe sooner than June so that the child can get more practice and more experiences of the skills that maybe the school is looking for when they arrive. So the longer they have at practicing, the more ready they are. You know we kind of really keep suggesting they go to an [Ontario] Early Years [Centre]. And they have to practice and you know we talked about [how] if a child is very attached to mummy or daddy that they have [practice] little bit of separation [and] trust building. And then when it comes to September, they should be a lot more prepared for school. [Jessica, p.12]

I think you would probably be more effective closer to the school year for a longer period of time so 2-3 weeks in August. Well my program started in the last week of august, so the child only needed to wait that weekend-you know Sunday, Monday, Tuesday they went to school. So they knew-and they still had those expectations in their mind. So they knew exactly what to expect. Personally, if you do it in June, I believe they've lost what they've been doing, what they've learned to a certain extent and when they start school in September, they're re-learning 
again. So I think it should be done closer to the beginning of the school year. [Mary, 5]

While more research needs to be done in order to determine when would be best to hold such programs, it is important to note that the School Readiness program offered by the OEY is providing a service to families in that they are recognizing this critical period in a child's life (Landry, Swank, Smith, Assel, \& Gunnewig, 2006) and trying to address that by running the program in order to facilitate the transition to school. It appears that each CDC had a different level of preparedness while conducting the program. While there was a lack of consistency between each CDC's program, it was apparent that while they were not provided with any clear guidelines into how to run the School Readiness program, the CDCs, especially Lisa and Mary, naturally oriented themselves and the way they ran their programs to preparing the child for school. It should be noted, however, that even with no specific guidelines, documents are available that provide guidance such as the Early Years Report. It is apparent from the interviews, that experiential knowledge defined each CDCs definition of school readiness. Di Santo (2006) suggested that early childhood educators' perceptions on school readiness may influence program quality. Hence, formalized training may be necessary in order to provide adequate services to children and families. The study looks at only two Toronto ridings. As different ridings may have different needs according to the demographic of the area, this variable needs to be taken into consideration when trying to create a program. This is not to say that if a more standard program of school readiness were created that it would meet all families' needs but that a framework for what a good school readiness program would entail needs to be in effect. Anyone running the program would then be able to use such a framework to develop and deliver a program that could be more finely tuned to meet the particular needs of that 
community. For example, when referring to ACF's (2007) conceptual framework (Appendix A), the ultimate goal is the child's competence, which is achieved through four cornerstones: the staff who conduct the programs, the child who will be part of the program, the involvement of the parents, and the support of the community. Those conducting the School Readiness program need to look further into how they can utilize all resources in order to achieve their ultimate goal.

The overall goal of the CDCs was to provide parents and children with a realistic idea of what to expect once the children began attending school in September. Enlisting the support of the community (i.e. the library and the schools) was beneficial in that it allowed parents to become aware of the community support available to them. The CDCs ran the School Readiness programs alone, which they all found to be quite difficult; however, as was seen, they were able to find a way to include both parents and children in accordance with the philosophy of the OEY- that is that they provided the opportunity for parent/caregiver - child interactions by developing programs and activities for children in the school readiness program that promoted early learning and literacy as well as optimal child development (MCYS, 2005). Encouraging participation in the School Readiness program as well as attending other OEY programs or any other community programs is noteworthy in that large scale studies have shown the benefits to children (i.e. with respect to cognitive, language, socio-emotional development) who attend such programs (ACF, 2007; Monkeviciene, Mishara, \& Dufour, 2006).

For the most part, materials used in the program consisted of crafts and activities for the children; however, there were also materials given to parents. This consisted of handouts that were used to inform parents of what they may need for Kindergarten as well as how to help prepare their children for school. However, in Jessica's group, one workshop had parents completing the Nipissing Developmental Screen used to help monitor children's development. 
Although, the screen and other assessment tools may be useful in helping parents see whether their children are developing as expected (NDDS, n.d.), for the purposes of the program, it may be more beneficial to focus on whether a child is ready to learn and what characteristics s/he exhibits or needs to develop in order to be prepared (Denham, 2006). In addition, the Nipissing checklist was administered in English. This poses two problems. One is that parents whose first language is not English may have a hard time understanding the checklist or recognize what it is for, thus causing undue concern to parents who may answer 'no' to some of the items. In addition, some items are asterisked to indicate that they may not be common to all cultures and so checking 'no' on the checklist may reflect more of a cultural variation in a child's upbringing rather than a developmental delay (NDDS, n.d.). If this is the case, then program planners need to figure out how to inform parents of what qualities their children need to develop in order to succeed in a Canadian school while keeping in mind the cultural variations that may exist with respect to a child's development as suggested by Barbarin, McCandies, Early et al. (2006). In addition, this tool and others may not be appropriate to be used in culturally diverse settings, unless the items on the checklist are real markers of a child's readiness to learn.

4.2 To what extent do the Ontario Early Years Centres School Readiness Program as run by the CDCs prepare children for school?

The School Readiness programs run by the CDCs incorporated literacy and numeracy as well as socio-emotional components, although to varying extents. The objective of this section is not to discuss who had more of what component; however, what is apparent-especially in Mary's and Lisa's School Readiness programs-is that literacy and numeracy were not considered a separate component from teaching social skills. Rather, the activities the children took part in incorporated all of them in a seamless way. Landry, Swank, Smith, Assel, \& 
Gunnewig (2006) found in their study of Head Start sites that incorporating literacy activities did not take away from a child learning socio-emotional skills and that repetition and consistency in learning is required to help children develop necessary skills. In addition, incorporating learning into everyday activities such as singing, dancing, and playing were found to be effective ways of teaching social competence to children (Lobo \& Winsler, 2006). For example, Lisa had her groups create name tags for themselves so that they would learn where they had to sit in circle. At first, the children were unable to find where they had to sit, but as she mentioned, at the end they could recognize at least the first letter of their names. During circle, some activities such as singing and reading stories were done in a group. Not only were children learning about literacy and numeracy, but they were learning social skills such as sharing, working together, and asking for what they needed—skills that some of the children did not have and that some parents were unaware that their children were not capable of doing. Activities for learning were not restricted to the program. Parents were given examples of things they could do with their children at home such as reading, counting steps, as well as practicing everyday skills such as dressing themselves and eating on their own.

As only one CDC used questionnaires in order to receive feedback, it was apparent that there was a lack of follow up with respect to whether or not the program was in fact a success once the children began school in September. One possible reason for the lack of follow up, aside from the time it would take to gather such data, may be that there was no consensus on what the school readiness program should entail and hence no evaluation tool to assess it's effectiveness. In addition, the question arises as to how the government is accounting for the success of the programs they fund. What types of data are collected by these agencies? Is it merely qualitative- numbers of people attending a program- or are these statistics corroborated 
with qualitative data as well? If the Ontario Early Years Centres claim that programs are quality and research-based, then where is the data that shows how the programs have prepared children for school readiness (OEYC, 2004)? When asked how they were able to measure change in children, the CDCs were able to provide a comparison of how the children were on the first days of their program in relation to the end of the program. Examples given in the results section reflect a similar trend across groups in that most children tended to be shyer and less likely to participate initially whereas at the end they were interacting with each other and they had learned what was expected of them. The CDCs looked at the development of each individual child and how that child evolved from start to finish rather than comparing them. This type of qualitative assessment is what is encouraged by professionals as children cannot be studied separate from their environment and each one may be influenced differently (Best Start Expert Panel on Early Learning, 2006). This is important because by recognizing the individual needs of a child and community, programs may be tailored to meet specific, demonstrated needs thus making it more likely for programs to generate equitable outcomes.

\subsection{Was there any indication of a difference between those who participated versus those who}

\section{did not?}

Of the three CDCs, Jessica and Mary felt that there was no difference or that it would be hard to say. Interestingly enough, Schneider, Ramsay, and Lowerson (2006) did not find a difference re: school readiness attainment (i.e. literacy and numeracy) between children who attended a Sure Start program versus those who did not. They did, however, find a difference in children's social scores, which may indicate that the purpose of such programming -and/or where the programs would make the most difference-is with respect to teaching children the social skills necessary to function and succeed in school and beyond. Lisa felt that there was a 
difference in this regard, and the examples she gave centered around the social skills that children were developing as well as how the program helped parents see what their children needed to work on.

Although Mary and Jessica cited several instances where children were developing their skills or parents were learning about various aspects of their children's development, the CDCs differed in their perception of whether it was necessary to make a school readiness program a compulsory part of getting children ready for school. Both emphasized having children attend some kind of program, although not necessarily a school readiness program of the type described in this study. In addition, while a school readiness program may be beneficial to some families, some families may have already been bringing their children to an OEYC or other child-centered program in which case many of the skills learned in the program may already have been developed. What seems important then is that children attend a program that helps them develop social skills and help them learn what is expected of them as suggested by the TDSB. For example, the TDSB suggests on its site that children who will be attending school the following fall should be able to let their needs be known to other children and adults, share materials and resources with others, and use a variety of materials for various activities (TDSB, n.d.), all of which was offered or taught to some extent by the School Readiness programs run by the CDCs.

\subsection{What are the positives outcomes and challenges faced while conducting the program?}

While it is not the intention of the researcher to discuss how or why the following have occurred, this section will be taken into account when making recommendations for improvement. In addition, many of the positive outcomes as well as challenges have been, to some extent, discussed in other sections. 
Among the positive outcomes mentioned was the coming together of the community in order to run the program, parents learning about community resources as well as having their questions answered, groups of children being able to visit the kindergarten classroom and in one instance use an unused classroom, and children learning new skills as well as what was expected of them when they started school.

Among the challenges mentioned was the issue of space and location where class was held, language barriers, parents impacting on children's learning, and the CDCs having to conduct the program on their own.

\subsection{Implications for immigrant families?}

It was interesting to note the comment Lisa made with respect to the Ontario Early Years Centres. When asked about the demographics of the families attending the OEYCs she explained that the OEYCs do not differentiate between newcomers and Canadians. Part of the uncertainty and fear around identifying newcomer status of participants may be that there are no guidelines on how to respond to the different needs without evoking the specter of race and racism. However, there are important cultural considerations that can impact on the delivery of the school readiness and other programs. Recognizing the various needs of different cultures and finding a way to meet them does not take away from the universal perspective of the OEYC. Hence, it is important to consider how this may be done. One practical consideration would be to conduct school readiness programs in other languages in order to make the program more accessible to diverse populations. As Mary mentioned briefly, she was able to converse with a lot of Hispanics in her program because she spoke the language. 
Participating in the school readiness program has major implications for immigrant families. Becoming informed about the school system is one of the greatest benefits of attending the program. Many parents are not aware of what their children need to know and what their children should be able to do when they go to school. Previous experience as well as cultural variations in early childhood learning expectations may influence the way some newcomer parents interact with the schools (Hoover-Dempsey, Walker, Sandler, Whetsel, Green, Wilkins et al, 2005), for example seeing a teacher or the school as experts and so refrain from questioning what goes on when in fact they have rights. Also, some cultures place a greater emphasis on developing literacy and numeracy skills and, as was seen in Jessica's explanation of her practice, the CDC can help parents see that there is an important social component that children need in order to succeed and the important role they the parents play in helping their children get ready in this area. By informing parents of what they need to know, what they can do, and letting them know their rights give them the opportunity to become active participants in their children's education, even if English is not their first language (Golan \& Peterson, 2002).

The supportive networks that formed as a result of parents attending the program with their children are also invaluable. Many immigrants face isolation and a lack of support when they arrive, especially if they have no family or friends around. Research has found that there are benefits to having a supportive group of people that one can turn to and this has resulted in parents becoming more active in their children's education (Bernhard, Freire, Pacini-Ketchabaw, and Villanueva, 1998). For some parents who could not speak or read the language, others who could were able to translate information so that there was a dissemination of information. 
Children were also found to benefit from the program. For immigrant children, cultural variations may exist as to what children should be able to do at their age (Barbarin, McCandies, Early et al, 2006). Aditionally, Maggi, Kohen, Hertzman, and D'Angiulli (2004) assert that those who reside in lower income neighbourhoods may be at even greater risk due to the fact that their cultural needs are not being met. Recognizing that there may be differences helps in that one can see areas of development that a child may need to work on in order to succeed in a Canadian school system. This is not to say that other methods of learning are not good but that there are certain expectations around school readiness for children in Canadian society and in Ontario schools and, by giving that information to families, one is helping them to better adapt to their new environment as parents' support is imperative to the effectiveness of the program (Driessen, Smit, \& Sleegers, 2005). School readiness programs then may be beneficial to all families but especially for immigrant families who are at an even greater disadvantage because in cases where English is not a first language, they are less able to communicate their needs and ask questions and may not be aware of what it is they need to know to prepare their children for school.

\subsection{Recommendations:}

1. A curriculum needs to be developed for the OEY School Readiness program. The curriculum need not be so stringent that one cannot deviate from it and those running the program cannot adapt it and/or adopt new activities and incorporate information to meet the needs of their specific communities and participating families. As was noted, a program including all three components- literacy, numeracy, and socio-emotional-would be most effective. Dissemination of information to parents is important; however, the overall goal of the program 
should be to prepare the children for school and show them what will be expected of them. Parents are then able to see what they need to work on with their children. A review of what the school wants children to learn or be able to learn is critical.

2. Feedback and Evaluation need to be received from both parents as well as teachers in order to assess the effectiveness of the program. This will also help in determining when would be the best time to hold such programs in order to maximize its benefits as the School Readiness program has been held at different times of the year.

3. The CDCs all mentioned the difficulty they experienced in conducting the program on their own. More supports are necessary in order to provide better services to the families. Thus, one recommendation is that, where possible, CDCs be given some assistance so that they do not overstretch themselves in trying to meet the individual needs of parents and children.

4. Additionally, some kind of formalized training may be beneficial in order that those running such programs be made aware of the various theories and current research in the area especially as the OEYC claims that their programs are research-based (OEYC, 2004). Considering that agencies are being held accountable to report on the success of their programs, it would behoove the government to invest more in training so that a better analysis of effectiveness can occur. Program success cannot be about numbers alone.

5. Attending the School Readiness program may not be as important as attending programs where children can socialize and gain those socio-emotional skills 
needed to succeed later in school. As such, the researcher recommends that families attend some kind of early years programming as this is an alternative way of learning the social skills research has found to be so necessary for children to succeed in the long and short term.

6. Programs were conducted in English. The possibility of conducting the program in other languages or with specific cultural groups may be a consideration, especially if certain populations have specific needs that need to be addressed.

7. A means for reaching immigrant families needs to be addressed. As they would benefit greatly from the programs, figuring out alternative means for reaching them is necessary. Letters sent to homes via the school may not be efficient in reaching these families as they may not even read or speak the language.

Alternative means of communicating with them and building relationships may greatly increase their participation in their children's education as well as provide their children with a more equitable start.

\subsection{Limitations of the Study}

One limitation to the study is that the researcher was unable to assess the program from the parents' perspectives due to time constraints. Interviewing program workers alone may provide only a one sided view of the program. Future research may wish to include parents in the interview process to help corroborate what the program workers are thinking and feeling with respect to how the program impacts on children and families. A second limitation results from the small number of people who have had experience preparing for and conducting the School Readiness program. Hence the small sample size was dictated by current realities of the program. Another limitation is that the Ontario Early Years is not the only agency that offers a school 
readiness program. Future research may wish to compare school readiness programs offered by various agencies to look for similarities, differences, and exemplary practices. 


\section{References}

Administration for Children and Families (2006). About Head Start. Retrieved February 12, 2007 from http://www.acf.hhs.gov/programs/hsb/about/index.htm.

Administration for Children and Families (2007). Executive Summary. Retrieved September 10, 2007 from

http://www.acf.hhs.gov/programs/opre/ehs/survey ehs/reports/findings ehs/findings ehs ex esum.html.

Albanese, P. (2005). "Ethnic families" In Maureen Baker (Ed.), Families: Changing trends in Canada (pp.121-142). Toronto: McGraw-Hill.

Ali, M. \& Kilbride, K. (2004). Forging new ties: Improving parenting and family support services for new Canadians with young children. Human Resources and Skill Development Canada.

Barbarin, O., McCandies, T., Early, D., Clifford, R., Bryant, D., Burchinal, M. et al. (2006). Quality of prekindergarten: What families are looking for in public sponsored programs. Early Education and Development, 17(4), 619-642.

Bernhard, J., Freire, M., Pacini-Ketchabaw, V., Villanueva, V. (1998). A Latin-American parents' group participates in their children's schooling: parent involvement reconsidered. Canadian Ethnic Studies, 30(3), 77-98.

Best Start (n.d.) Best Start. Retrieved January 7, 2008 from http://www.beststart.org/about_us/index.html. 
Best Start Expert Panel on Early Learning (2006). Early learning for every child today- $A$ framework for Ontario early childhood settings. Retrieved September 10, 2007 from http://www.children.gov.on.ca/NR/CS/Publications/en elf.pdf.

Bryman, A. \& Teevan, J. (2005). Social Research Methods: Canadian Edition. Ontario: Oxford University Press.

Canadian Mothercraft Society (2006). Ontario Early Years Centres. Retrieved December 21, 2007 from http://www.torontodacs.net/dispatcher.asp?page=105.

Canadian Mothercraft Society (2006b). Ontario Early Years Centres- St.Pauls. Retrieved December 22, 200 from http://www.mothercraft.ca/dispatcher.asp?page=171\&sub=202.

Community Social Planning Council of Toronto (n.d.). Provincial Early Years Centres One Stop Shopping, One Size Fits All?. Retrieved December 22, 2007 from http://www.socialplanningtoronto.org/Soundbite/Bite33.htm.

Creswell, J. (2005). Educational Research. Upper Saddle River, New Jersey: Pearson Education Inc.

Denham, S. (2006). Social-emotional competence as support for school readiness: What is it and how do we assess it? Early Education and Development, 17(1), 57-89.

Department for Children, Schools and Families (2007). Sure Start. Retrieved on January 5, 2008 from http://www.surestart.gov.uk/.

Di Santo, A. (2006). School readiness: Perceptions of early childhood educators, parents, and preschool children. Doctoral dissertation, University of Toronto, Toronto, ON. 
Driessen, G., Smit, F., \& Sleegers, P. (2005). Parental involvement and educational achievement. British Educational Research Journal, 31(4), 509-532.

Family Day Care Services (2005). Ontario Early Years Centres. Retrieved December 22, 2007 from http://www.familydaycare.com/oeyc.html.

Fiorentino, L. \& Howe, N. (2004). Language competence, narrative ability, and school readiness in low-income preschool children. Canadian Journal of Behavioural Science, 36(4), 280294.

Glutting, J., Barker, W., \& Gelardo, M. (1983). Effects of student attributes on kindergarten scores across product and process tests. Journal of Psychoeducational Assessment, 1, 261-271.

Golan, S. \& Petersen, D. (2002). Promoting involvement of recent immigrant families in their children's education. Harvard Family Research Project. Retrieved September 15, 2007 from http://www.gse.harvard.edu/hfrp/projects/fine/resources/research/golan.html.

Graue, E. (2006). The answer is readiness - now what is the question? Early Education and Development, 17(1), 43-56.

Gredler, G. (1997). Issues in early childhood screening and assessment. Psychology in the Schools, 34(2), 99-106.

Hoover-Dempsey, K., Walker, J., Sandler, H., Whetsel, D., Green, C., Wilkins, A. et al. (2005). Why do parents become involved? Research findings and implications. The elementary school journal, 106(2), 105-131. 
Janus, M. \& Duku, E. (2007). The school entry gap: Socioeconomic, family, and health factors associated with children's school readiness to learn. Early Education and Development, 18(3), 375-403.

Kershaw, P., Forer, B., Irwin, L, Hertzman, C., \& Lapointe, V. (2007). Toward a social care program of research: A population-level study of neighbourhood effects on child development. Early Education and Development, 18(3), 535-560.

Landry, S., Swank, P., Smith, K., Assel, M., \& Gunnewig, S. (2006). Enhancing early literacy skills for preschool children: Bringing professional development model to scale. Journal of Learning Disabilities, 39(4), 306-324.

Lapointe, V., Ford, L., \& Zumbo, B. (2007). Examining the relationship between neighbourhood environment and school readiness for kindergarten children. Early Education and Development, 18(3), 473-495.

Lewitt, E. \& Baker, L. (1995). School readiness. The Future of Childre, 59(2), 128-139.

Lobo, Y. \& Winsler, A. (2006). The effects of a creative dance and movement program on the social competence of Head Start preschoolers. Social Development, 15(3), 501-515.

Maggi, S., Kohen, D., Hertzman, C., D'Angiulli, A. (2004). Effects of neighborhood socioeconomic characteristics and class composition on highly competent children. The Journal of Educational Research, 98(2), 109-114.

Macaulay Child Develoment Centre (2005). Ontario Early Years Centres. Retrieved December 22, 2007 from http://www.macaulaycentre.org/earlyyears.html. 
Maxwell, K. \& Bryant, D. (2001). North Carolina school readiness assessment battery.

Retrieved January 8, 2006 from http://www.fpg.unc.edu/ SchoolReadiness/battery.pdf.

Ministry of Children and Youth Services (2003). Ontario Early Years Plan: A Report to Ontario

Families. Retrieved December 21, 2007 from

http://www.children.gov.on.ca/NR/CS/oeyi/OEYParep.pdf.

Ministry of Children and Youth Services (2005). Ontario Early Years Centres. Retrieved

February 12, 2007 from http://www.ontarioearlyyears.ca/oeyc/en/home.htm.

Ministry of Children and Youth Services (2007). About Ontario's Best Start. Retrieved

September 10, 2007 from

http://www.children.gov.on.ca/mcys/english/programs/beststart/index.asp.

Ministry of Children and Youth Services (2007b). Best Start: Helping young children get the best start in life. Retrieved February 12, 2007 from

http://www.children.gov.on.ca/CS/en/programs/BestStart/default.htm.

Ministry of Children and Youth Services (2007c). The Early Years Study 1999. Retrieved December 21, 2007 from

http://www.children.gov.on.ca/mcys/english/resources/publications/beststart-early.asp.

Monkeviciene, O., Mishara, B., \& Dufour, S. (2006). Effects of the Zippy's Friends programme on children's coping abilities during the transition from kindergarten to elementary school. Early Childhood Education Journal, 324(1), 53-60. 
Momirov, J. \& Kilbride, K. (2004). Family lives of native peoples, immigrants and visible minorities. In Nancy Mandel (Eds.), Canadian Families: Diversity, Conflict and Change. (pp 87-110). Toronto, ON: Thomson Nelson

Nipissing District Developmental Screen (n.d.). Frequently asked questions. Retrieved November 9, 2007 from http://www.ndds.ca/ontario/faq.html.

Ontario Early Years Centre (2004). Starting right: A better tomorrow for children- A report from Ontario Early Years Centres Toronto network. Toronto, ON: Ontario Early Years Centre

Prochner, L. \& Cleghorn, A. (2005). Cross-cultural research as a lens on early childhood thought and practice. In Pence, A. \& Pacini-Ketchabaw, V. (Eds). Canadian Early Childhood Education: Broadening and Deepening Discussions of Quality, 59-76. Ottawa, ON: Canadian Child Care Federation.

Schneider, J., Ramsay, A., \& Lowerson, S. (2006). Sure Start graduates: predictors of attainment on starting school. Child Care, Health \& Development, 32(4), 431-440.

Shields, J. (2004). No safe haven: Markets, welfare and migrants. In P. Kretsendemas \& A. Aparacio (eds.), Immigrants, Welfare Reform and the Poverty of Policy (pp.35-60). New York: Praeger.

SIRCH Community Services and Consulting (n.d.).:Welcome to School's Cool. Retrieved December 22, 2007 from http://www.schoolscool.org/.

Snow, K. (2006). Measuring school readiness: Conceptual and practical considerations. Early Education and Development, 17(1), 7-41. 
Statistics Canada (2007). Immigrant population by place of birth, by province and territory (2006 census). Retrieved January 5, 2008 from http://www40.statcan.ca/101/cst01/demo34b.htm.

Toronto District School Board (2006). Our children, our schools: The 2006 environmental scan of the TDSB. Retrieved January 5, 2007 from http://www.tdsb.on.ca/wwwdocuments/about_us/environmental_scan_2007/docs/Rev4OurChildrenOurSchools.pdf.

Toronto District School Board (n.d.). Starting kindergarten in the TDSB. Retrieved November 8, 2007 from http://www.tdsb.on.ca/_site/ViewItem.asp?siteid=96\&menuid=321\&pageid=249. 


\section{Appendix A: Conceptual Framework Created by ACF}

Figure 1. Conceptual Framework for Programs Serving Infants and Toddlers

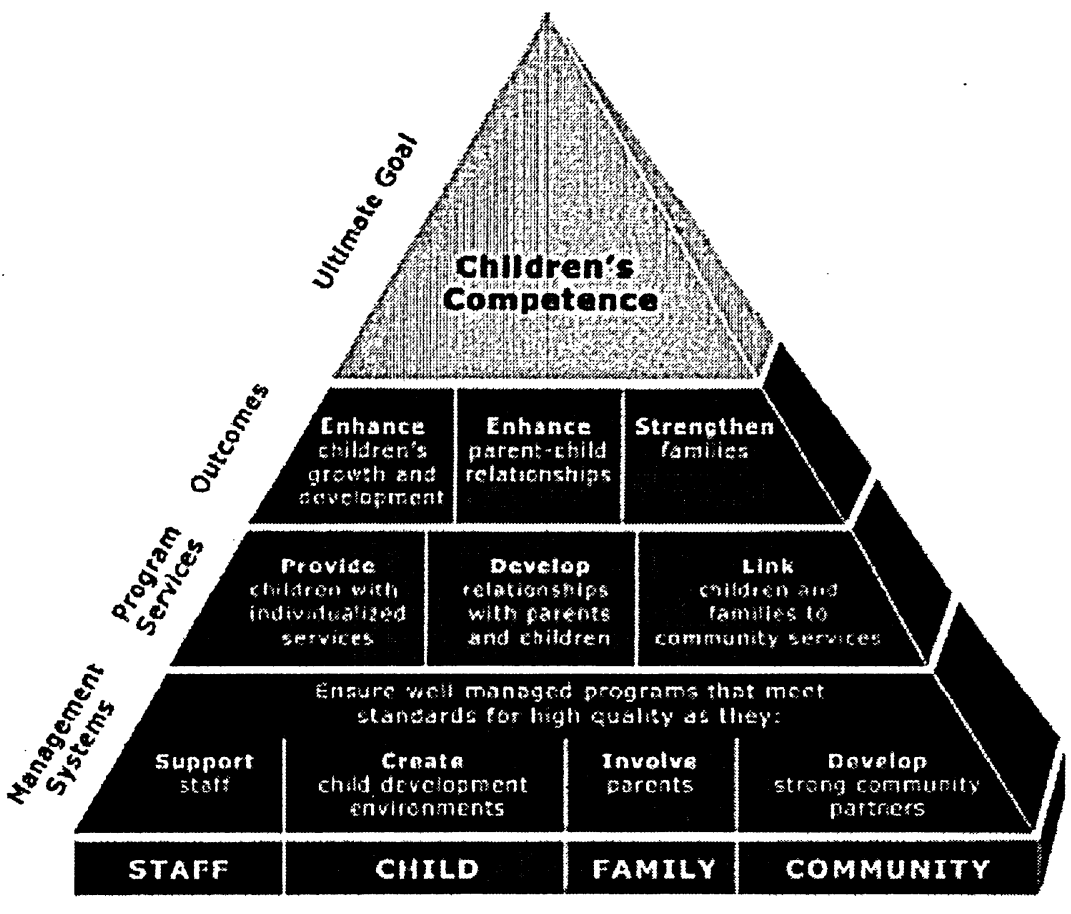

Cornerstones

http://www.acf.hhs.gov/programs/opre/ehs/survey ehs/reports/findings ehs/findings ehs exesum.ht

$\underline{\mathrm{ml}}$ 


\section{Appendix B: Principles for Early Child Development and Parenting Programs}

The following principles lay the foundation for the early child development and parenting program:

1. Early child development and parenting centres that are available, accessible, affordable and optional for all young children and families in Ontario from conception to entry into grade one in the school system (parents may choose to bring their children or not);

2. Quality parenting and early child development centres that are both parent-oriented and childoriented;

3. Early child development programs that are environments for children to engage in play-based, problem-solving learning with other children and adults;

4. Responsive relationships between adults (early child development staff and parents) and children that increase the potential of play-based learning;

5. Quality programs that teach family literacy and numeracy to parents and other caregivers from diverse cultural, ethnic and linguistic backgrounds;

6. Parenting programs that support parents and other caregivers in all aspects of early child development;

7. Parent participation in early child development programs that enhances the child's early learning and optimal development in the home environment;

8. Appropriate supports and expertise that are available to allow all children to participate fully, regardless of physical, developmental, language, learning or behaviour difficulties;

9. Ability to provide special efforts that may be necessary to engage some families and children whose circumstances make it difficult for them to be involved in the early child development and parenting centres;

10. Early child development and parenting centres, regardless of location, that are linked to the local primary school and with other institutions such as libraries, recreation, and cultural activities in their communities;

11. Early child development and parenting centres that provide a flexible continuum of services to meet the needs of children and parents at home, at work and in school; and 
12. The effectiveness of early child development centres that are monitored using a developmental readiness-to-learn measure when children enter the school system

http://www.children.gov.on.ca/mcys/documents/publications/beststart-early-en.pdf (pg. 138-139) 


\section{Appendix C: Toronto District School Board's Getting Ready for School}

\begin{tabular}{|c|c|}
\hline At school children will: & At home you can: \\
\hline Encounter new people and situations. & $\begin{array}{l}\text { Involve you child in new situations where they will meet } \\
\text { new people (e.g., going to the library for storytime). }\end{array}$ \\
\hline Communicate needs to other children and adults. & $\begin{array}{l}\text { Encourage your child to use language to make his/her } \\
\text { needs known (e.g., going to the washroom, getting a } \\
\text { drink) and to solve problems (e.g., when sharing with } \\
\text { others). }\end{array}$ \\
\hline Dress themselves to play outside and to go home. & $\begin{array}{l}\text { Encourage you child to put on jacket, boots, snowpants, } \\
\text { etc. independently. }\end{array}$ \\
\hline $\begin{array}{l}\text { Make choices (e.g., activities in the class, materials to } \\
\text { use). }\end{array}$ & $\begin{array}{l}\text { Help you child make choices (e.g., which clothes to wear, } \\
\text { activities to do). }\end{array}$ \\
\hline Share materials and spaces with other children. & $\begin{array}{l}\text { Give your child opportunities to be with other children, } \\
\text { share, and take turns. }\end{array}$ \\
\hline $\begin{array}{l}\text { Listen to stories, poems, and information. They will look } \\
\text { at, talk about, and read books on their own and with } \\
\text { others. }\end{array}$ & $\begin{array}{l}\text { Tell stories, say poems, and sing songs in your own } \\
\text { language. Read to your child and talk about the pictures, } \\
\text { ideas, and words. Point out signs, words, and numbers } \\
\text { in the home and community. Visit the library together. }\end{array}$ \\
\hline $\begin{array}{l}\text { See adults and other children write for different } \\
\text { purposes. They will use materials such as crayons, } \\
\text { markers, and pencils for drawing and writing their own } \\
\text { ideas. }\end{array}$ & $\begin{array}{l}\text { Involve your child in drawing and writing in everyday } \\
\text { activities at home (e.g., making cards, signing own name, } \\
\text { drawing pictures). Praise your child's attempts to draw } \\
\text { and write. Talk about your child's name and the letters in } \\
\text { it. }\end{array}$ \\
\hline $\begin{array}{l}\text { Explore nature in the world around them and talk about } \\
\text { what they see and learn. }\end{array}$ & $\begin{array}{l}\text { Talk to your child about the things you see and hear } \\
\text { outside and on walks in the community. Point things out } \\
\text { (e.g., changes in the weather, the seasons, construction, } \\
\text { etc.). }\end{array}$ \\
\hline $\begin{array}{l}\text { Learn about numbers, shapes, patterns, estimating, and } \\
\text { measuring. They will talk about their ideas and what they } \\
\text { are learning. }\end{array}$ & $\begin{array}{l}\text { Talk about numbers, shapes, and patterns at home and } \\
\text { outside. Play games together (matching and counting, } \\
\text { cards, simple board games). When cooking, let your } \\
\text { child help with measuring ingredients. Involve your child } \\
\text { in sorting (e.g. toys, clothes, putting away groceries). }\end{array}$ \\
\hline $\begin{array}{l}\text { Create art, explore and use art materials, build } \\
\text { structures, take part in music, drama, and movement } \\
\text { activities. }\end{array}$ & $\begin{array}{l}\text { Encourage your child's imagination and creativity through } \\
\text { drawing, building, singing, moving to music, and acting } \\
\text { out stories. }\end{array}$ \\
\hline $\begin{array}{l}\text { Use a variety of materials and equipment to develop } \\
\text { large and small muscles. }\end{array}$ & $\begin{array}{l}\text { Provide opportunities for your child to exercise and use } \\
\text { large muscles (e.g., running, climbing, playing with a ball) } \\
\text { and small muscles (e.g., using crayons or markers, } \\
\text { playdough, puzzles or toys with pieces that fit together). }\end{array}$ \\
\hline
\end{tabular}

You are your child's most important teacher.

http://www.tdsb.on.ca/_site/ViewItem.asp?siteid=96\&menuid=321 \&pageid=249 


\section{Appendix D: Consent Form}

\section{Ryerson University: Consent Agreement}

\section{Assessing the Effectiveness of an Ontario Early Years Centre: Parent Involvement and School Readiness}

You are being asked to participate in a research study. Before you give your consent to be a volunteer, it is important that you read the following information and ask as many questions as necessary to be sure you understand what you will be asked to do.

The research is being conducted by Ziba Saadati, an MA Early Childhood Studies student at Ryerson University being supervised under Dr. Hyacinth Simpson. The study will be looking at the school readiness program offered by the Ontario Early Years Centres. In addition to reviewing the materials used in the program, staff members who have had experience running the program will be asked to participate in a taped interview so to help the researcher gain more insight into the program offered and its benefits and challenges to children and families. The research will be conducted at the Ontario Early Years centre where the staff members work and each one-on-one interview will last approximately 30 minutes. None of the interview questions used in this study are experimental in nature. The only "experimental" aspect of this study is the gathering of information for the purpose of analysis.

The study aims to provide a critical assessment of an important educational service with an aim to assisting in improving the province's educational programming for young children. Staff members who participate in the interview are providing valuable insight and information as to whether or not the programs are meeting the needs of parents and children. A report of the researcher's analysis of the programs and suggestions for improvement will be submitted to the program supervisor, Michael Ashton; however, please note that at no time will any quotes from the interviews be used in order to protect your privacy. Direct non-attributable quotes will only be used for the purposes of my major research paper and any presentations or publications that may arise from it.

Please note that because the questions require some personal reflection on your individual experiences in the program, if at any time you feel uncomfortable, you may choose not to answer the question or we may stop the interview if you so choose. If you feel more comfortable meeting at a site outside of the early years, this may be arranged at your request. Your choice of whether or not to participate will not influence your future relations with Ryerson University. If you decide to participate, you are free to withdraw your consent and to stop your participation at any time without penalty or loss of any benefits to which you are allowed. Please be aware that your responses are private and at no time will your responses be revealed to your program supervisor or the Ontario Early Years through any direct quotes. The analysis provided by the researcher will be from the researcher's perspective after review of the interviews and the program materials and will in no way identify any of the participants or responses in order to 
protect your identity and employment.

At any particular point in the study, you may refuse to answer any particular question or stop participation altogether. Participants may withdraw participation at any time. Participation in this study is voluntary and there are no incentives-financial or otherwise-for taking part in the interview.

Please be aware that all interviews will be kept confidential and the identities of participants will remain anonymous. Recordings will be kept in a locked cabinet with the researcher's supervisor for a period of 5 years at which point they will be destroyed. If you have any questions about the research now, please ask. If you have questions later about the research, you may contact me at zsaadati@ ryerson.ca or my supervisor at simpson@ ryerson.ca or 416-9795000 ext 6148 .

If you have questions regarding your rights as a human subject and participant in this study, you may contact the Ryerson University Research Ethics Board for information.

Research Ethics Board

c/o Office of the Associate Vice President, Academic

Ryerson University

350 Victoria Street

Toronto, ON M5B 2K3

416-979-5042 


\section{Agreement:}

Your signature below indicates that you have read the information in this agreement and have had a chance to ask any questions you have about the study. Your signature also indicates that you agree to be in the study and have been told that you can change your mind and withdraw your consent to participate at any time. You have been given a copy of this agreement.

You have been told that by signing this consent agreement you are not giving up any of your legal rights.

Name of Participant (please print)

Signature of Participant

Date

Signature of Investigator

Date

By signing below you are acknowledging your consent to be audio taped for the purposes of this study.

Signature of Participant

Date

Please note that at no time will the audio taped interviews be made public. Although no names or identifying pieces of information will be used in order to protect your identity, please check below if you do not wish any direct comments to be quoted in my major research paper.

I do not wish any direct comments to be quoted in your major research paper or any presentations or publications. 


\section{Appendix E: Questionnaire Used During Interview}

Intro Questions:

- Tell me about the OEYC?

- What do you do in the program/ what is your role?

- Could you explain some more about the program- the people who work in it etc.

- What other programs are being run? What is your demographic?

- Ask a question about immigrant communities and then follow through depending on her answer.

- So you just recently ran the school readiness program, could you tell me more about it?

\section{Interview Questions}

1. Tell me how the school readiness program is run here at the Ontario Early Years.

a. What is a typical day like in the program

b. What is the length of the program

c. What is the decision process in deciding what materials to use

d. How is it promoted- is it pre-registered, invitation only; who is being asked to participate in the programs

2. To what extent do you feel that you are preparing children for school readiness with respect

to: $* *$ interested in personal assessment/response to these questions ${ }^{* *}$

a. Literacy and numeracy

b. Socio-emotional competence

c. How do you quantify/measure these outcomes?

3. Do you feel there is a difference between children and parents who participate in the program versus those who do not? ${ }^{* *}$ prompt for anecdotal; information here as support**

a. If yes, what are these differences? Can you please elaborate and give some examples of the differences you see.

b. If no, why do you think this is so? (i.e. Is it because the program does not meet the needs of the families?)

4. What are some of the positive outcomes that you have seen as well as the challenges that you faced when conducting the program? **ask question in more casual way**

a. In general, what are your feelings?

b. How effective has the program been in regard to preparing newcomer children for school readiness and incorporates their parents into the pogram? Are there any noticeable differences in the needs of newcomer children and non-immigrant families? If so, how is the program responding to these differences? What are the 
benefits/challenges these families face when entering the school system and what do you perceive the school readiness program has done for them?

5. What do you feel are the benefits and challenges to running these programs and meeting the needs of the families?

a. How would you improve it?

b. What would you keep?

c. What can be done to better meet the needs of families and children especially those who are immigrants to Canada? 